\title{
The Separation Power of Nanotubes in Membranes: A Review
}

\author{
Bart Van der Bruggen \\ Laboratory for Applied Physical Chemistry and Environmental Technology, Department of Chemical Engineering, KU Leuven, \\ W. de Croylaan 46, 3001 Leuven, Belgium
}

Correspondence should be addressed to Bart Van der Bruggen, bart.vanderbruggen@cit.kuleuven.be

Received 20 March 2012; Accepted 1 May 2012

Academic Editors: W.-J. Chang, B. Coasne, Y. Jin, Y. A. Koksharov, and Y. Li

Copyright ( $) 2012$ Bart Van der Bruggen. This is an open access article distributed under the Creative Commons Attribution License, which permits unrestricted use, distribution, and reproduction in any medium, provided the original work is properly cited.

\begin{abstract}
Research on mixed matrix membranes in which nanoparticles are used to enhance the membrane's performance in terms of flux, separation, and fouling resistance has boomed in the last years. This review probes on the specific features and benefits of one specific type of nanoparticles with a well-defined cylindrical structure, known as nanotubes. Nanotube structures for potential use in membranes are reviewed. These comprise mainly single-wall carbon nanotubes (SWCNTs) and multiwall carbon nanotubes (MWCNTs), but also other structures and materials, which are less studied for membrane applications, can be used. Important issues related to polymer-nanotube interactions such as dispersion and alignment are outlined, and a categorization is made of the resultant membranes. Applications are reviewed in four different areas, that is, gas separation, water filtration, drug delivery, and fuel cells.
\end{abstract}

\section{Introduction}

The use of nanoparticles has a long history. Nanoparticles were used by artisans as far back as the 9th century in Mesopotamia for generating a glittering effect on the surface of pots. This was denoted as "luster art," which refers to a metallic film applied to the transparent surface of a glazing, consisting of $\mathrm{Cu}$ or $\mathrm{Ag}$ nanoparticles. In this way, beautiful iridescent reflections of different colours (in particular gold and ruby-red) are obtained [1]. This was of interest in Muslim art, where no gold was to be used for decoration. The first scientific description of nanoparticles, however, was given in 1857 by Michael Faraday, who studied the sizedependent optical properties of gold and silver colloids or nanoparticles [2]. In the modern era, and in de last decade in particular, insights and discoveries in the field of nanostructures are booming. This stems generally from the fact that nanoparticles form a bridge between bulk materials and atomic or molecular structures; a bulk material should have constant physical properties regardless of its size, whereas a molecular structure may show discrete differences [3].

Nanoscience is the study of phenomena and the manipulation of materials at the atomic or molecular level. Nanotechnology involves the design, production and use of structures through control of the size and shape of the materials at the nanometer scale [4]. There is, however, some ambiguity with respect to what exactly should be considered as nanomaterials. Especially when nanomaterials are used in macroscopic structures, this might be somewhat unclear. This is the case for membranes used for separations; even though there is evidence for pore sizes in the nanometer range for membranes used in nanofiltration [5-7], such membranes should probably not be considered nanomaterials. Mueller et al. [8] emphasize that according to the definition of the International Union of Pure and Applied Chemistry (IUPAC), the term "nano" in nanofiltration refers to the size of the particles rejected and not to a nanostructure as defined by the International Organisation of Standardisation (ISO). A nanomaterial is defined [9] as a material with any external dimension in the nanoscale or having an internal structure or surface structure in the nanoscale. A nanostructure is a composition of interrelated constituent parts, in which one or more of those parts is a nanoscale region. A nanoobject is an object with any dimension in the nanoscale.

In general, however, the size of nanoparticles should be between 1 and $100 \mathrm{~nm}$. Nanomaterials are of interest in many applications. For example, Morris [4] describes the use of nanomaterials in the food industry, where the definition 
and regulation of engineered nanomaterials is of particular interest and concern. In human health care, nanoparticles are of interest in a wide range of applications, such as diagnostics and therapeutics [10], cancer therapy [11], and drug delivery [12].

The use of nanoparticles in chemical and environmental engineering is of interest in (photo) catalysis [13-15] and in the development of hybrid membranes, often denoted as mixed matrix membranes [16]. Several different terms are currently being used such as nanoactivated, nanoenhanced, nanoparticles-enhanced, nanoparticles-based and nanofunctionalized membranes. All of these have a hybrid structure in which nanosized objects are present, which entails potential risks for release to the environment, ecotoxicity, or human toxicity [17]. The effect, however, seems to be closely related to the upper aerodigestive tract, and cytotoxic and genotoxic effects could be found [18]. Environmental effects are also of concern, including their release to the aquatic environment; potential risks are related to bioavailability and uptake into cells and organisms. From this, it is concluded that a precautionary approach is required with individual evaluation of new nanomaterials for risk to the health of the environment [19]. Thus, release of nanoparticles to the environment remains a challenge in all applications; the effect of specific nanoparticle properties and the measurement of nanoparticle concentrations in the environment are still unclear [20].

The interest of using nanoparticles in membrane structures mainly focuses on their assumed beneficial effect on fluxes and fouling resistance. Kim and Van der Bruggen [21] reviewed potential applications of nanoparticles-enhanced membranes in general. They conclude that the use of nanoparticles in the development of low-fouling membranes allows for a high degree of control over membrane characteristics as well as the ability to produce ceramic membranes in the nanofiltration membrane range. A wide range of nanoparticle types are used, such as $\mathrm{TiO}_{2}$ [22-25], ZnO [26], $\mathrm{Al}_{2} \mathrm{O}_{3}$ [27, 28], $\mathrm{Au}$ [29], zero-valent iron (ZVI) [30], Pd [31], and others. According to Pendergast and Hoek [32], the most promising functionalities in water treatment applications include zeolitic and catalytic nanoparticle-coated ceramic membranes, hybrid inorganic-organic nanocomposite membranes, and bioinspired membranes such as hybrid proteinpolymer biomimetic membranes, aligned nanotube membranes, and isoporous block copolymer membranes.

This review focuses on the use of nanotubes in membrane structures, their functionalities, applications and challenges for future research. An evaluation is made of the stateof-the-art and research progress in the field of mixed matrix membranes based on nanotubes. Eventually, a prognosis is made of the future development of the use of nanotubes enhanced membranes.

\section{Potential Types of Nanotubes and Properties}

A nanotube is a nanometer-scale tube-like structure. The best known nanotubes (and most widely used) are carbon nanotubes, but other materials are also used as nanotubes.
These are often composed of metal oxides, but their morphology is always very similar to carbon nanotubes.

All nanotubes have an extremely high aspect ratio in common, which makes them to molecular-level needles. They can penetrate into cell membranes and may therefore have functionalities on cellular level. For example, they can be used for cancer treatment when they can be directed to those cells that are infected, for delivery of specific drugs. Nanoparticles allow exquisite modification for binding to the membrane of a cancer cell, or to cytoplasmic or nuclear receptor sites. This allows the delivery of high concentrations of drugs to the targeted cancer cell, with reduced toxicity for uninfected cells [33]. Another interesting feature is the electral conductivity of (carbon) nanotubes. The diameter and the helicity of carbon atoms in the nanotube shell are believed to determine whether the nanotube is metallic or a semiconductor [34], which can be used in, for example, the development of specific sensors [35] for detection of carbon monoxide [36] or other chemicals [37]. This is due to a change in electrical conductivity when other molecules are attached to the nanotubes. The limitation is that in principle only molecules binding to a carbon nanotube can be detected, such as $\mathrm{NH}_{3}, \mathrm{NO}_{2}$, and $\mathrm{O}_{2}$. However, by doping of impurity atoms (e.g., boron, nitrogen atoms) into single-wall carbon nanotubes or by using composite $\mathrm{B}_{x} \mathrm{C}_{y} \mathrm{~N}_{z}$ nanotubes, these limitations can be overcome so that toxic gases (including CO) can be detected as well [38]. This is also possible when combining carbon nanotubes with gold nanoparticles for detection of $\mathrm{NO}_{2}, \mathrm{CO}$, and $\mathrm{C}_{6} \mathrm{H}_{6}$ [39].

A third particular characteristic of nanotubes is their mechanical strength. Nanotubes are the strongest materials known, but the ultimate limits of their strength have yet to be reached experimentally [40]. Because nanotubes can be viewed as "rolled-up" graphene sheets, and because graphite is exceptionally strong with respect to inplane deformations, nanotubes possess extraordinary mechanical properties. An extensive discussion of bending and elastic deformation and the tensile strength of nanotubes, including modeling of nanotubes-based composites, is given by Bernholc et al. [40]. This also allows their use as additives for reinforcement of composite materials based on polymers [41]. This can be used over a wide range of conditions, as shown by Oliver et al. [42] at temperatures down to $77 \mathrm{~K}$.

The thermal properties of nanotubes have been less investigated but may be equally interesting. Theoretical work predicts a room-temperature thermal conductivity that is larger than graphite or diamond [43]. Measurements show a room-temperature thermal conductivity over $200 \mathrm{~W} / \mathrm{m} \mathrm{K}$ for bulk samples of single-walled nanotubes (SWNTs), and over $3000 \mathrm{~W} / \mathrm{m} \mathrm{K}$ for individual multiwalled nanotubes (MWNTs).

One of the more recently researched properties of MWNTs is their wave absorption characteristics, specifically microwave absorption [44-46]. Under microwave irradiation, SWNTs quickly reach temperatures of approximately $1850^{\circ} \mathrm{C}$. This might also be significant for development of radar absorbing materials (RAM).

As stated, the material most studied as nanotubes thus far is carbon [47]. Thus, all derived studies such as the use 
of nanotubes in membranes, focuses almost exclusively on carbon nanotubes; this review, therefore, mainly describes membranes enhanced by carbon nanotubes. Nevertheless, it should be understood that nanotubes exist also made of noncarbon materials, usually metal oxides. These might play an important role in the future, which is at present not yet understood. For example, Levy et al. [48] developed a method for synthesis of rare-earth manganese-oxidebased nanotubes. They obtained structures of nominal composition $\mathrm{La}_{0.325} \mathrm{Pr}_{0.300} \mathrm{Ca}_{0.375} \mathrm{MnO}_{3}$ with $800 \mathrm{~nm}$ external diameter, $4000 \mathrm{~nm}$ length, and wall thickness below $100 \mathrm{~nm}$ exhibiting magnetic and magnetoresistive behavior below $200 \mathrm{~K}$, including nonvolatile memory. Using a manganese oxide template, this opens the way to composite nanotubes and nanotubes of polymeric nature, when the template is selectively removed. This is shown for polyaniline templates by Pan et al. [49]. Combining carbon nanotubes with manganese oxide is useful for the development of film electrodes [50].

Other metal oxides used for nanotubes include vanadium oxide $[51,52]$. Again, the multiwalled material contains template molecules between the individual shells, which by a simple cation exchange can be removed without destruction of the tubes. These nanotubes can be synthesized fairly easy and in a cost-effective way $[53,54]$.

The group of Tremel in Germany managed to produce tin sulfide nanotubes, using bismuth nanodroplets as a catalyst [55]. This allowed for nucleation and growth of $\mathrm{SnS}_{2}$ nanotubes.

Tungsten disulfide $\left(\mathrm{WS}_{2}\right)$ and molybdenum disulfide $\left(\mathrm{MoS}_{2}\right)$ are further material with specific interest for nanotube configurations [56]. Furthermore, it has been shown that traditional ceramics like titanium dioxide $\left(\mathrm{TiO}_{2}\right)$ and zinc oxide $(\mathrm{ZnO})$ also form inorganic nanotubes [57] although this is still in an early stage of development.

Using other dopants such as lithium on carbon nanotubes extends the application range even more, to, for example, lithium batteries [58]. Carbon nanotubes are often used as a base material, for doping and/or coating. Whitby et al. [59] applied a $\mathrm{WS}_{2}$ coating as an antioxidizing agent to MWCNs, by pyrolyzing $\mathrm{WO}_{3}$-coated multiwalled carbon nanotubes in an $\mathrm{H}_{2} \mathrm{~S} / \mathrm{N}_{2}$ atmosphere at $900^{\circ} \mathrm{C}$. Rhenium(IV) sulfide nanotubes were synthesized by carbon nanotube templating as well [60]. The literature in this field is extensive, and it is beyond the scope of this paper to give a complete overview of nanotubes based on other materials than carbon. Nevertheless, the materials mentioned above should be considered of potential interest for membrane applications as well. Applications in the literature on nanotubes enhanced membranes, however, focus on carbon nanotubes; this will be outlined in the following sections.

\section{Categories of Carbon Nanotubes}

Carbon nanotubes [61] belong to the family of fullerenes, and are categorized into single-walled nanotubes and multiwalled nanotubes. Single-walled carbon nanotubes are oneatom-thick sheets of graphite, resembling chicken wire [62], and rolled into a tubular form. The walls are formed by one-atom-thick sheets of graphene. Multi-walled carbon nanotubes consist of multiple concentric rolled layers of this material in tubular shape. This is shown in Figure 1. The diameter of a carbon tube can be several nanometers, but their length is much larger, with aspect ratios that go as high as 132,000,000 [63]. Many terms and acronyms are used in the scientific literature to describe carbon nanotubes; both "-wall" and "-walled" can be found, as "single," "double," "triple" or "multi"-wall(ed) nanotubes. The acronym may or may not contain the letter C; multi-walled carbon nanotubes can be abbreviated as MWNT or MWCNT. In this review, carbon nanotubes will be referred to as SWCNT or MWCNT.

Special configurations of nanotubes are nanobuds and nanotori. Nanobuds were developed for the first time in 2007 by Nasibulin et al. [64] as hybrid fullerene SWCNTs, in which fullerene-like buds are covalently bonded to the outer sidewalls of the underlying carbon nanotube. This is shown in Figure 2 [65]. Compared to nonhybridized nanotubes, nanobuds have been shown to have exceptional magnetic $[66,67]$ properties. Multilayer nanobuds form a porous network structure with surface areas above $2000 \mathrm{~m}^{2} / \mathrm{g}$, which was suggested to be of use for gas storage [68].

A nanotorus [69] is a bended nanotube, found to have extraordinary properties, such as very high magnetic moments [70]. Properties are shown to vary widely on radius of the torus and radius of the tube [71]. Figure 3 shows the structure of a nanotorus [71]. Other carbon nanotube configurations reported are carbon peapods, in which fullerenes are trapped into a carbon nanotube [72, 73], cup-stacked carbon nanotubes with large hollow core [74], single-wall carbon nanohorns [75], and carbon nanotube-buckyball systems, in which a buckyball is attached to single-walled carbon nanotube (SWCNT) at one end and the other end of SWCNT is fixed [76]. Cup-stacked carbon nanotubes are excellent as supports for Pt-Ru catalysts [77] and have been synthesized with a diameter of $80-120 \mathrm{~nm}$ and a hollow channel of $60-100 \mathrm{~nm}$ along the nanotube axis [78]. This configuration is shown in Figure 4 [79]. For carbon peapods, however, stability is probably compromised since it was shown that the axial stability is less than that of a carbon nanotube under identical conditions [80].

Carbon nanotubes may be used as such, or they can be modified by grafting of chemical functions at the surface of the nanotubes to add new properties. Even though many hybrid membrane structures with nanotubes used nonfunctionalized SWCNTs or MWCNTs, the planned modification of SWCNT properties is believed to open the road towards real nanotechnology applications [81]. In the case of SWCNTs, covalent functionalization is used to break $\mathrm{C}=\mathrm{C}$ double bonds, and to attach functional groups. Many examples can be found of functionalized SWCNTs, such as grafting of p-methoxyphenyl [82], functionalization with adenosine monophosphate [83], covalent addition of 4-benzo-9crown-3 ether diazonium salt [84], and many more. Noncovalent modifications are also applied [85], although these are very specific for given applications such as dispersing SWCNTs in a water matrix [86]. The use of electron-donor and -acceptor molecules is outlined by Ghosh et al. [87]. 

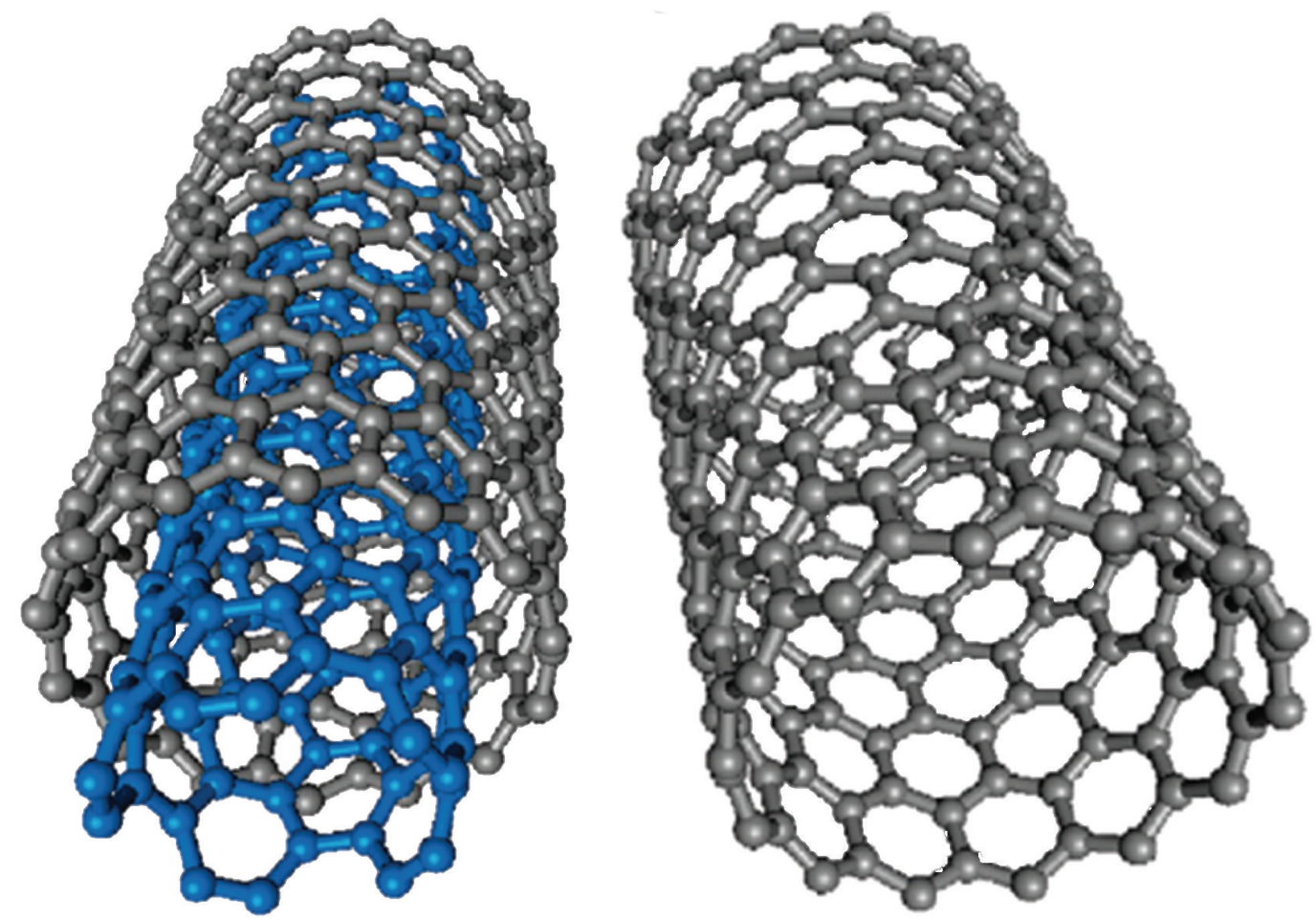

Figure 1: (a) Structure of a multiwall carbon nanotube (MWCNT) and (b) structure of a single-wall carbon nanotube (SWCNT). Reprinted with permission from Zhao and Stoddart [189]. (Copyright (2009) American Chemical Society.)

In the case of MWCNTs, only the outer wall is usually modified. The advantage of MWCNTs, having a morphology and properties similar to those of SWCNT but with improved resistance to chemicals, also implies that modification is less straightforward. Grafting of chemical functions at the surface of the nanotubes to add new properties is carried out with similar methods as for SWCNTs. Covalent functionalization can be carried out with, for example, polymers [88], by carboxylation and nitration for increasing sorption characteristics [89], by covalent functionalization with e caprolactam or L alanine for increased biocompatibility [90], and by the formation of an ester linkage between lipase and MWCNTs for biocatalyst and biosensor activities [91]. Noncovalent functionalization of MWCNTs is less reported; functionalization by pyrene-PEG molecules through pi-pi stacking [92] and by adsorption of $\mathrm{H}_{2} \mathrm{NCH}_{2} \mathrm{CH}_{2} \mathrm{ONa}$ [93] has been reported. Even though not yet common in hybrid membrane technology, such modifications are thought highly important because progress in carbon nanotubes enhanced membranes is to be expected from these modified and/or tuned materials.

\section{The Use of Nanotubes in Conjunction with Polymers}

A groundbreaking publication that triggered research on nanotubes in membrane structures appeared in 2004. Hinds et al. [94] incorporated an array of aligned carbon nanotubes across a polymer film to form a well-ordered nanoporous membrane structure. One important aspect was the tuned reduction of the length of the nanotubes within the polymer film by selective electrochemical oxidation, which resulted in carboxylate end groups that were readily functionalized at the entrance to each nanotube. However, developing polymeric membranes enhanced by nanotubes requires a fundamental understanding of the interactions between nanotubes and polymers in hybrid matrices [95, 96]. For example, polypropylene composites have been studied extensively; the effect of surfactants such as sodium dodecyl sulfate (SDS) and sodium dodecylbenzene sulfonate (NaDDBS) on the on morphological, rheological, thermal, crystalline, mechanical, and electrical properties of MWCNT/PP (polypropylene) nanocomposites has been systematically investigated [97]. Other studies focus on dielectrical properties [98], morphological aspects [99], creep and recovery [100], or mechanical properties [101].

Numerous publications can be found on nanocomposites with many other polymers, such as ethylene-vinyl acetate copolymer [102], polyvinylidene fluoride [103], polyolefins [104], acrylonitrile-butadiene-styrene [105], polyphenylene sulfide [106], poly(ethylene terephthalate) (PET) [107], and many more. Even though interactions between polymers and nanotubes are quite different from the projected functionality in membranes, the polymer-nanotube conjunction is a basic starting point showing a glimpse of the potential of hybrid materials. For a specific polymer, a targeted search for composites with carbon nanotubes can be easily made, as a reference point for further work. 

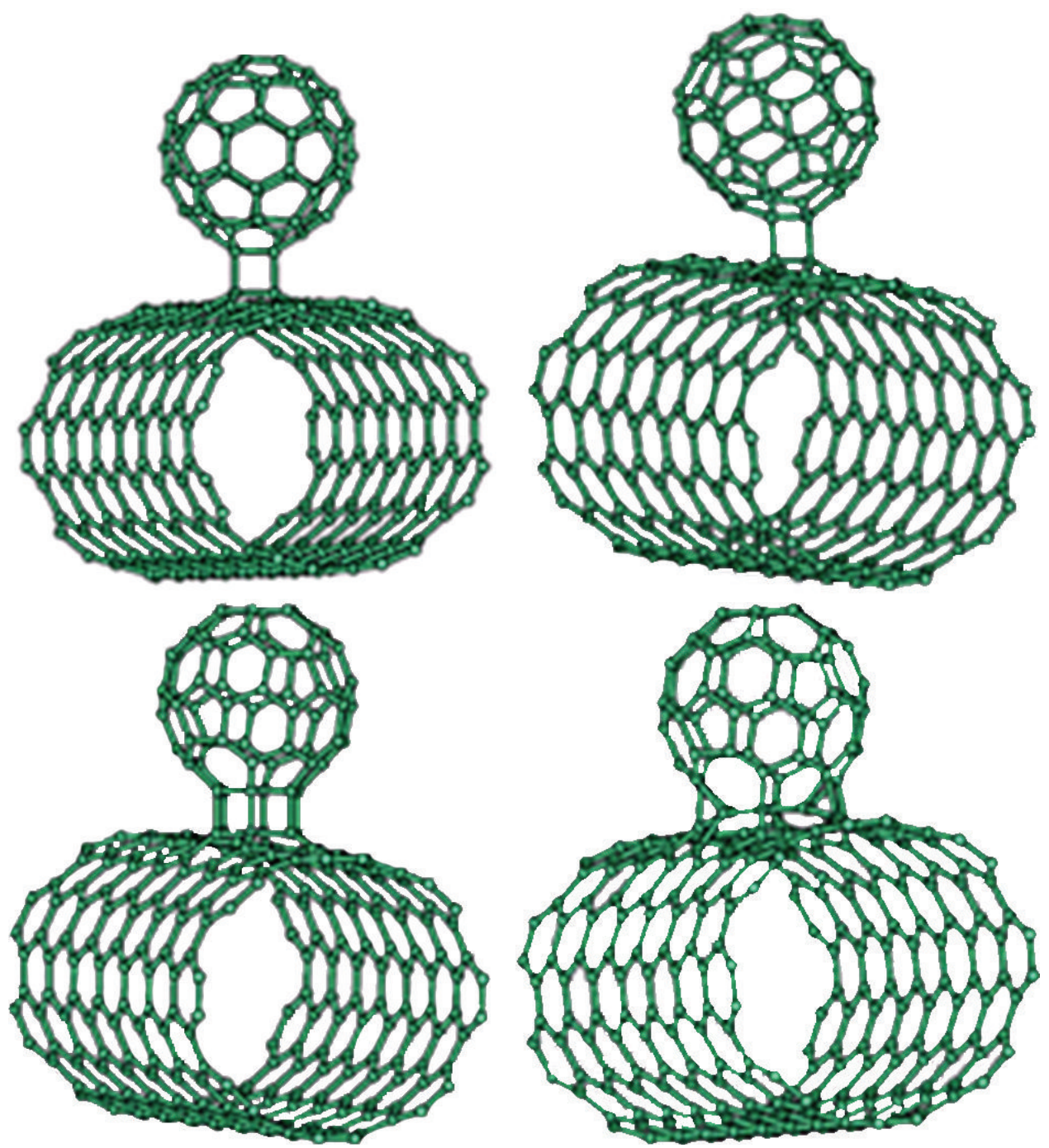

FIGURE 2: Structure of several stable carbon nanobud structures. Reprinted with permission from Wu and Zeng [68]. (Copyright (2009) American Chemical Society.)

The next step is to embed nanotubes in a polymeric matrix, which alters the conjunction since the polymer is now present as the continuous matrix. Loos and Schulte [108] state that although a great deal of work has been done toward using SWCNTs and MWCNTs as a reinforcing agent in polymer composites, the full potential has yet to be reached. They mainly conclude that in order to achieve the true potential of carbon nanotubes, several challenges have to be faced. Carbon nanotubes have to be produced with higher purity, longer lengths, better integrity, in larger amounts, and at lower cost. Moreover, issues such as orientation of the nanotubes, their concentration, interfacial adhesion, distribution, and dispersion have to be overcome. Nevertheless, it is widely understood that a small quantity of nanotubes can significantly increase the electrical properties of composites and lower the coefficient of thermal expansion [109]. Usually, superior mechanical properties are reported, which comprises many aspects such as tensile strength, compressive and flexural properties, and interlaminar, interfacial, and fracture strength. Crystallinity may also be influenced, which was shown for polypropylene by Razavi-Nouri [110]. Other related properties to be studied are the melting behavior [111], and thermal stability and flame retardancy [112].

Engineering of multiphase materials such as inorganic materials in a polymeric matrix is a basic challenge to eventually come to a well-designed, high-performance, reproducible membrane for separations. This is described in general by Supova et al. [113], who underline the importance of well-dispersed systems. Al-Saleh and Sundararaj [114] mention as determining factors in a mixed matrix structure (polymer/carbon nanotubes): dispersion and distribution, filler aspect ratio, adhesion and interface between filler and polymer matrix. The aspect of optimizing the polymernanotubes dispersion has been studied by several other authors as well. The ability to tune a dispersion of carbon nanotubes in polymers should be considered the key factor to the development and application of nanotube/polymer composites. Thess et al. [115] already underlined in an early 


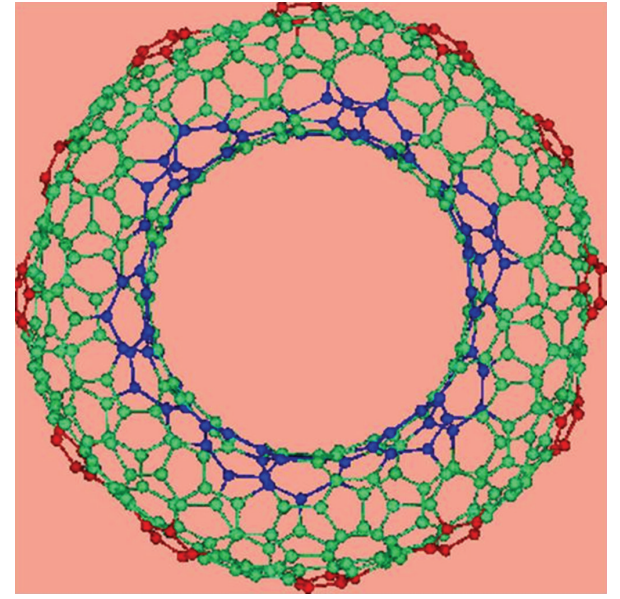

FIgURE 3: The geometry of a nanotorus. Reprinted from Sun [71].

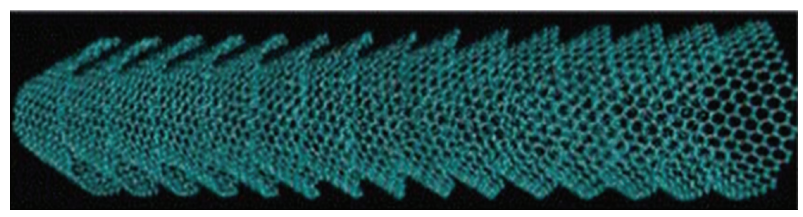

FIGURE 4: Atomic models of stacked-cup nanotubes. Reprinted with permission from Kim et al. [79].

stage that the bottleneck for using SWCNTs as fillers for polymer-based nanocomposites is that SWCNTs are held together in bundles of 50 to a few hundred individual nanotubes by very strong van der Waals interactions. A straightforward method to improve the dispersion is the addition of surfactants. Several studies can be found combining surfactants with polymers; for example, An et al. [116] studied the effect of hexadecyl trimethyl ammonium bromide (HTAB), sodium dodecyl sulfate (SDS), oleic acid, Triton X-100 and BYK-9077 in epoxy resin for MWCNTs, and concluded that BYK-9077 was the only surfactant which enhanced the dispersion homogeneity. Usually, however, the focus is on aqueous systems, with some studies related to solvents [117]. A comprehensive review for aqueous systems is given by Wang [118], who also outlines he thermodynamic driving forces and the role of metastability in the structure of surfactant dispersed SWCNT suspensions. Sonication is another method that can be applied (or rather, should be applied) for stabilization of carbon nanotube suspensions $[119,120]$. In general, this is found in publications as a standard experimental method and is thought necessary in most applications. Ultrasound allows to break the carbon nanotube bundles, and this makes the incorporation of individual nanotubes, or at least bundles as thin as possible, in the polymer matrix. However, a too aggressive or too long sonication treatment might lead to localized damage of the walls of a nanotube and to shortening of the nanotube [121].

Grossiord et al. [122] studied dispersions of nanotubes in view of the development of conductive nanocomposites; the methods that they indicate can be generalized. The objective is to obtain a three-dimensional network of nanotubes in the polymer matrix. They distinguish three methods for dispersing nanotubes (SWCNTs) into a polymer matrix. The first one is through direct mixing; as already stated, sonication is usually to be applied in this case. Nevertheless, some exceptions were reported, for example, in the work of Sandler et al. [123, 124]. They dispersed MWCNTs into an epoxy resin with relatively low viscosity by shear-intensive mechanical stirring, using a dissolver disk. Alternatively, they propose the use of a solvent to lower the viscosity of an epoxy resin, which favors the dispersion.

The second method is the functionalization of the walls of the nanotubes or the modification of the polymer matrix. Functionalization of carbon nanotubes has been described above; this usually concerns methods based on grafting. The degree of functionalization should be well balanced since a high degree of modification would affect the properties of the carbon nanotubes [125], which are the reason for using them, but a sufficient grafting effect is necessary to achieve compatibility between the polymer matrix and the carbon nanotubes. Examples of modifications are the grafting of poly(methyl methacrylate) [126] and of polystyrene [127]. Modification of the polymer can be done by using conjugated polymers, which can associate through $\pi-\pi$ interactions. For example, Chen et al. [128] used poly(phenylene ethynylene) (PPE) to disperse nanotubes; polyaniline and polyimide are also widely reported in this context [129-132].

The third approach is the use of a third component, which is usually a surfactant, as explained above. One potential alternative, however, is a conductive polymer, as shown by Ramasubramaniam et al. [133].

A final step to design polymer-carbon nanotube composites is the alignation of the nanotubes inside the polymer matrix. This yields controlled-morphology aligned carbon nanotubes in which the characteristics mentioned above can be used maximally, which is extremely important especially for membrane applications. Cebeci et al. [134] applied thermal chemical vapor deposition (CVD) to grow MWCNTs on silicon wafers. This allows to grow CNT "forests," as shown in Figure 5. Anisotropic behavior via morphology control can thus be induced, which is thought to be a critical factor to develop optimized membrane structures. Other methods for alignment include ex situ techniques, force and magnetic fields, electrospinning and liquid crystalline phase-induced methods [135].

\section{Membranes Enhanced with Carbon Nanotubes for Advanced Separations}

Using the knowledge on polymer-carbon nanotubes interactions, engineered macroscopic structures such as membranes for advanced separations can be developed. Such membranes fit into the approach of "mixed matrix membranes," for which a wide range of (inorganic) additives is used in a polymeric membrane matrix [136].

Sears et al. [137] distinguish two types of carbon nanotubes-derived membranes: (i) CNT bucky-papers, a nonwoven, paper like structure of randomly entangled CNTs 

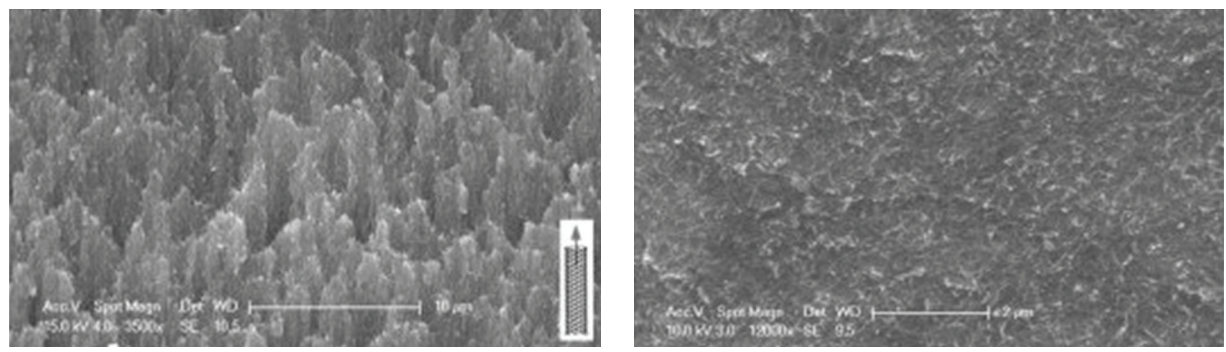

Figure 5: SEM images of a 1\%-aligned polymer-nanotubes composite (a), and a $4 \%$ random composite. Scalebars are $10 \mu \mathrm{m}$ and $2 \mu \mathrm{m}$, respectively. Reprinted with permission from Cebeci et al. [134].

and (ii) isoporous CNT membranes, where the hollow CNT interior acts as a membrane pore. CNT buckypaper is a mat of randomly entangled CNTs, prepared by filtration. This is a simple and robust method, yielding a membrane with high tensile strength (although this depends on the type of CNT used). They form a highly porous network of randomly orientated CNTs, although the CNTs predominately lie in a plane parallel to the Bucky-paper surface [137]. To control porosity and pore size, polymer beads are dispersed together with the CNTs to form a polymer/CNT Buckypaper composite, as shown in Figure 6 for polystyrene beads.

Bucky papers based on carbon nanotubes are hydrophobic and self-supporting and therefore perfect candidates to be used in (direct contact) membrane distillation, as shown by Dumee et al. [138]. To improve the mechanical stability while maintaining a high hydrophobicity, modifications by UV/ozone treatment to create hydroxyl groups and (ii) reacting those groups by substitution with alkoxysilanebased groups [139].

Isoporous membranes in which the nanotubes are used as transport channels are reported by Karan et al. [140]. They developed self-standing carbon layers with hydrophobic pores in the order of $1 \mathrm{~nm}$, which can be used for solvent separations on molecular level. Such isoporous membranes have extraordinary properties, as was already shown for desalination purposes by Hinds et al. [94]. Chen et al. [141] suggest that water transport is dominated by asymmetric wettability of the carbon nanotubes, which yields high fluxes and selective exclusion of ions. Nanoscale hydrodynamics indeed determine transport through the tubes, which is very different from for example, microscale hydrodynamics. Functionalization can alter these transport properties significantly. For example, plasma oxidation to introduce carboxylic acid groups on nanotubes that were modified using carbodiimide-mediated coupling between the carboxylic acid and an accessible amine groups of the functional molecule was shown to have a large effect for straight chain alkanes, anionically charged dye molecules, and an aliphatic amine elongated by polypeptide spacers [142]. This is schematically shown in Figure 7 [143]. This approach also opens the way to biomimetic membranes using nanotubes as channels [144].

Transport through nanotubes was reported already in 2001 for methane/ethane, methane/n-butane, and methane/ isobutene through single-walled carbon nanotubes [145], and in 2002 for gases [146]. Water transport through carbon nanotubes was considered by Joseph and Aluru [147], who further elaborate the effect of smoothness of the CNT surface on water transport. They show that the enhanced flow rates over Hagen-Poiseuille flow arise from a velocity jump in a depletion region at the water nanotube interface and that the water orientations and hydrogen bonding at the interface significantly affect the flow rates.

These studies underline the huge potential of such isoporous carbon nanotube membranes for application in gas separation and water purification. Understanding the effects of surface and nanotube properties, functionalization and smoothness can help in further optimizing membrane structures, particularly when they need to be developed for large-scale applications.

In a third type of CNT membranes, carbon nanotubes are randomly dispersed (typically without alignment) in a polymer matrix. They are often used as nanofillers, in a similar way as for example, titania or zeolites [148]. A schematic representation is shown in Figure 8 [136]. In some cases, modified nanotubes were used as filler material, as, for example, reported by Mansourpanah et al. [149] for the use of polycaprolactone-modified multiwall carbon nanotubes as additives for synthesis of PES membranes. Several other examples of such studies can be found, in which it is shown that membrane properties change when carbon nanotubes are added to the polymer matrix [150-153]. However, one could argue that only a limited number of features of nanotubes are exploited in this way (e.g., the hydrophobicity and high aspect ratio) and that the effects may be shielded by the surrounding polymer matrix, so that effects are much more limited than for isoporous membranes. Nevertheless, mixed matrix membranes have their own attraction and interest.

\section{Application Areas}

Four main application areas of nanotube-enhanced membranes are distinguished in this paper: gas separation, water treatment, drug delivery, and fuel cells. These are considered as the areas with the highest potential for implementation; nevertheless, this would by no means imply that other applications are thought not feasible. Several have potential in a more distant future but need to be further developed (which can be either related to the membranes, or to the process itself that needs maturation). One example 


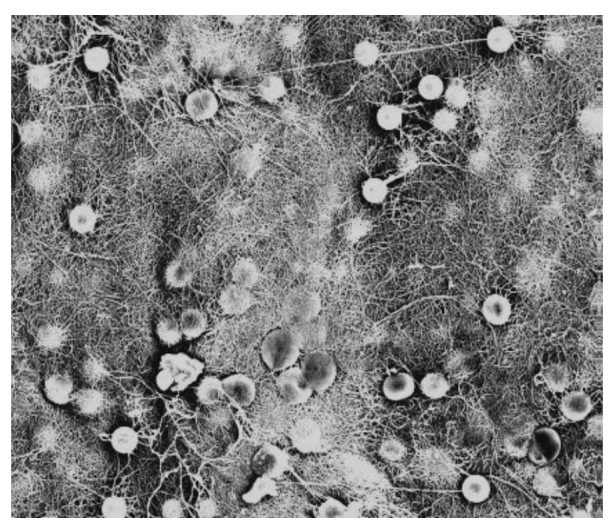

(a)

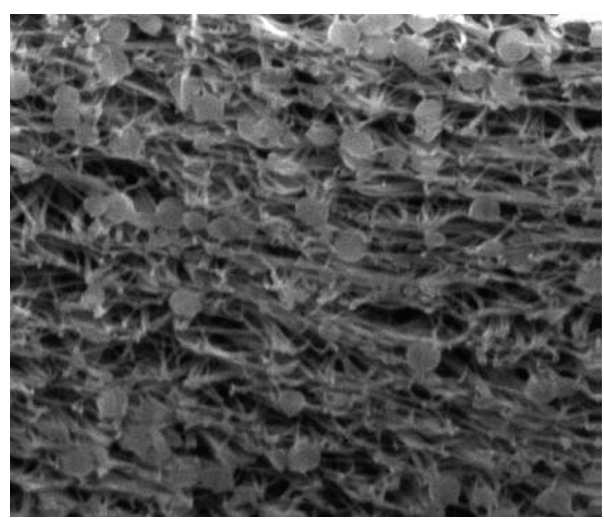

(b)

FIGURE 6: SEM images showing (a) the surface and (b) a cross-section ( $52^{\circ}$ sample tilt) of a Bucky paper formed from a mixed dispersion of PS beads and MWCNTs. The PS beads in (a) and (b) had $1 \mu \mathrm{m}$ and $100 \mathrm{~nm}$ diameters, respectively. Reprinted from Sears et al. [137].

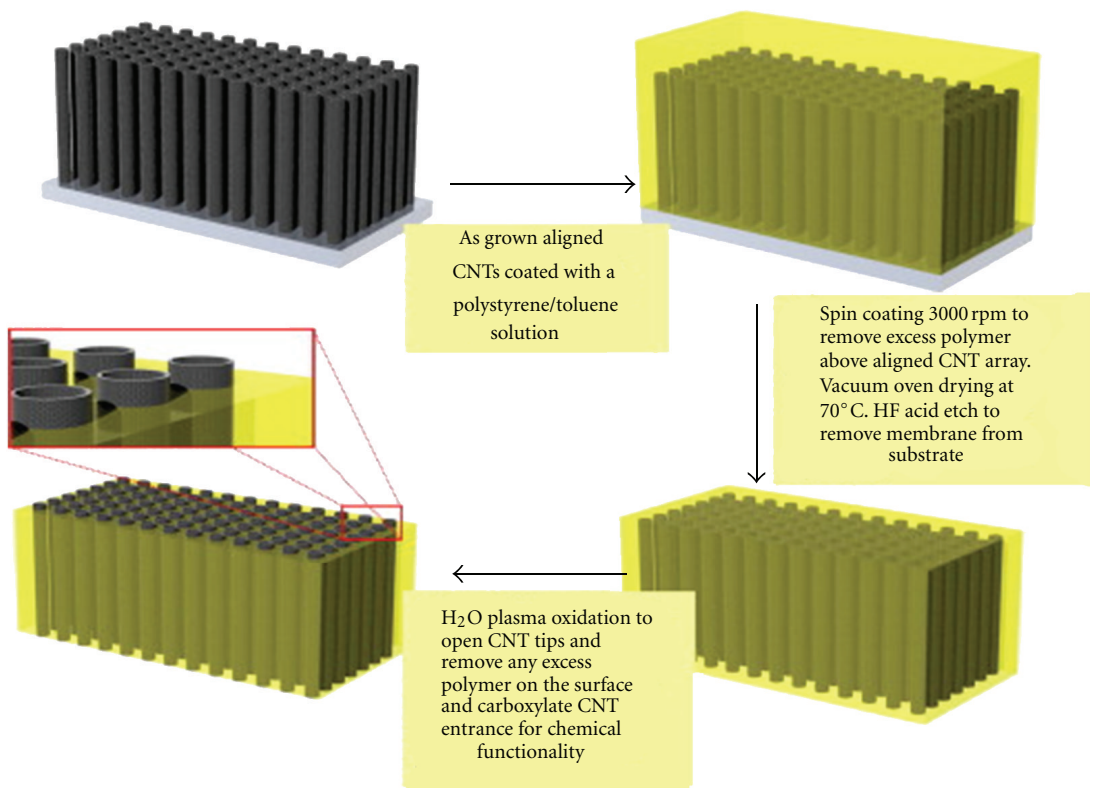

FIGURE 7: Schematic representation of isoporous CNT membranes and steps to be taken for membrane manufacturing and functionalization. Reprinted with permission from Hinds [143]. (Copyright (2011) Elsevier.)

already mentioned is membrane distillation using buckypaper membranes $[138,139]$, which is an interesting option but needs maturation. Pervaporation with CNT membranes $[153]$ is also less developed.

6.1. Gas Separation. The most mature application area for mixed matrix membranes and carbon nanotube membranes is gas separation. Goh et al. [136] reviewed recent advances in mixed matrix membranes for gas separation and described carbon nanotubes as one among three emerging fillers for membranes (the two others are metal-organic frameworks and clay-layered silicate). Not surprisingly, the interaction between the two phases is mentioned as one of the key factors for a successful integration; this confirms the analysis made earlier in this paper. They describe the phenomenon of "classification," which is defined as filler material separating out from the membrane matrix due to incompatibility; as a result, a separate filler phase is formed, which may deteriorate the gas separation performance of the membranes $[136,154]$. A bridging agent is needed to overcome this problem. This is shown in Figure 9 [136].

The development of mixed matrix gas separation membranes started on the basis of simulations proving the excellent features of carbon nanotubes for separating gases. Arora and Sandler [155] calculated the kinetic and ideal separation factors for a carbon nanotube membrane, and proved that for single wall carbon nanotubes, high permeances can be obtained along with good kinetic selectivities. 


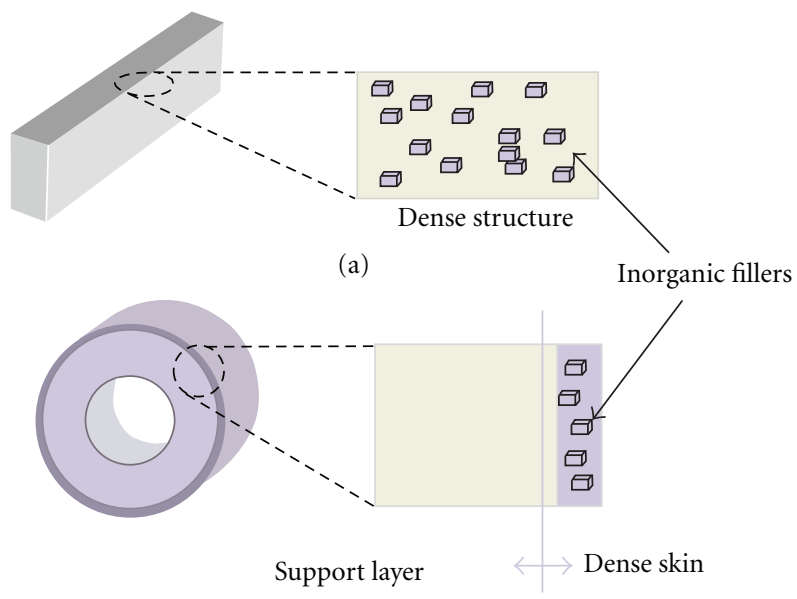

(b)

FIGURE 8: Schematic representation of flat sheet and hollow fiber-mixed matrix membranes. Reprinted with permission from Goh et al. [136]. (Copyright (2011) Elsevier.)

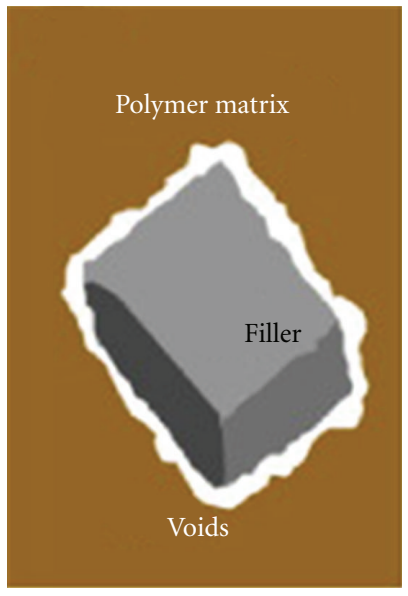

(a)

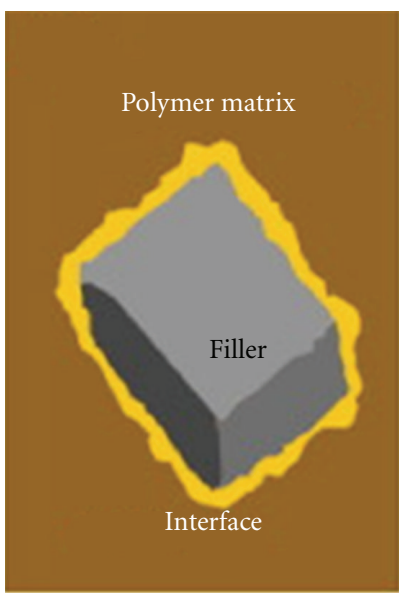

(b)

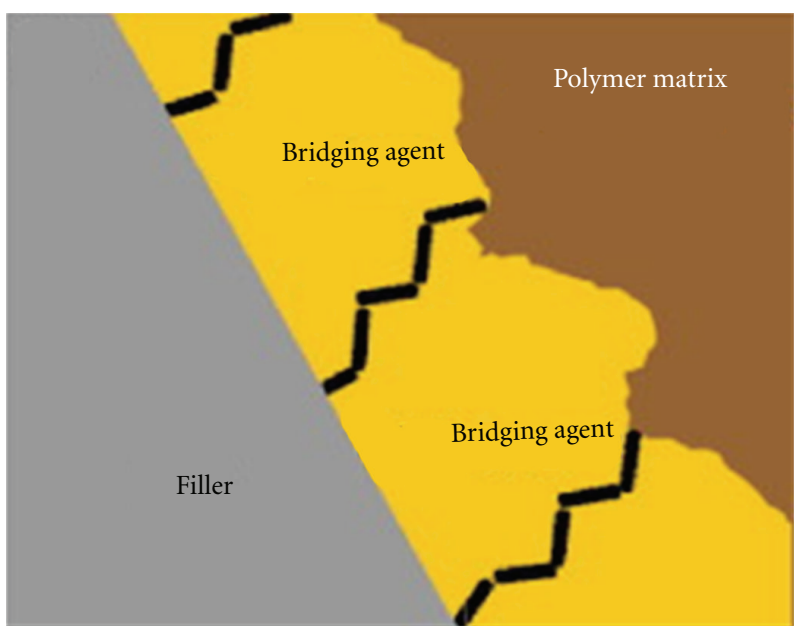

(c)

FIGURE 9: Role of bridging agents in mixed matrix membranes. Reprinted with permission from Goh et al. [136]. (Copyright (2011) Elsevier.)

Chen and Sholl [156] made atomic calculations to predict the separation between $\mathrm{CO}_{2}$ and $\mathrm{H}_{2}$ for SWCNTs and found a remarkable selectivity for $\mathrm{CH}_{4}$. Similar results were obtained for carbon dioxide-nitrogen separation [157]. Oxygen to nitrogen selectivity was further described by Arora and Sandler [158] by using molecular dynamics and grand canonical Monte Carlo simulations; this opened the way for air separations. Sangil et al. [159] described a simple procedure to produce carbon nanotube membranes with high performance.

For mixed matrix membranes, Gusev and Guseva [160] proved that nanotube/polymer membranes can favorably combine the high-flux performance of nanotubes with the intrinsic selectivity of a polymer matrix. Sharma et al. [161] dispersed MWCNTs and SWCNTs in polycarbonate and describe a procedure for aligning the nanotubes, using a DC-electric field of $500 \mathrm{~V} / \mathrm{cm}$. It appears that a better performance can also be obtained without this alignment procedure; nevertheless, it should be suggested to apply this in order to have a maximal benefit of the nanotubes. Several other studies can be found in which gas separation is studied for various systems using (often nonaligned) mixed matrix membranes, for hydrogen/methane separation [162], carbon dioxide/methane separation [163], hydrogen/carbon dioxide/oxygen/nitrogen [164], and carbon dioxide/nitrogen [152].

6.2. Water Treatment. One of the most fascinating areas of application of carbon nanotubes in membranes is desalination. Elimelech and Phillip [165] provide a clear evaluation of the current state of the art in desalination, including the potential of carbon nanotubes. They relate the extremely high water fluxes to the molecular smoothness of nanotube 
walls, the structure that water takes within nanotubes, and the smooth energetic landscape inside nanotubes. However, they also state that none of these mechanisms actually results in a selective rejection of dissolved salts, which means that chemical functionalities to the mouth of the nanotube pores should provide for that. Alternatively, the nanotube diameter should be small enough to sieve ions from solution based on size, but such membranes do not yet exist. Corry [166] makes a detailed calculation of these effects for nanotubes between 6 and $11 \AA$. It was shown that ions face a large energy barrier at the pore mouth when the channel is narrow enough. They do not pass through narrow tubes $((5,5)$ and $(6,6)$ "armchair" type tubes) but can pass through the wider $(7,7)$ and $(8,8)$ nanotubes. Thus, it can be concluded that more fine tuning in CNT membranes is needed for practical applications of desalination. This is confirmed by Lee et al. [167], who state that such novel materials represent the most likely opportunities for enhanced RO desalination performance in the future, but that a number of challenges remain with regard to their practical implementation. Hilder et al. [168] remark that boron nitride nanotubes may be of more interest than carbon nanotubes. Using molecular dynamics simulations they show that a $(5,5)$ boron nitride nanotube embedded in a silicon nitride membrane can, in principle, obtain 100\% salt rejection.

Nevertheless, carbon nanotubes are nowadays frequently used as additives for membranes in view of improving their performance. Zhao et al. [169] have reviewed procedures for synthesis of membranes with nanotubes incorporated, and suggest that nanofiltration membranes based on vertically aligned CNTs are the most promising, which corresponds to the above.

Shawky et al. [170] studied MWCNT/aromatic polyamide (PA) nanocomposite membranes to reject $\mathrm{NaCl}$ and humic acid. They concluded that rejections increased significantly; however, fluxes go down, which is a general trend for all nanoparticle-enhanced membranes [21]. Choi et al. [171] found a higher flux when incorporating MWCNTs, but the pore size depended on the concentration of nanotubes. The pore size of the blend membranes increased with the concentration of MWCNTs up to $1.5 \%$ and then decreased until it became even smaller than PSf membrane (at 4\%). This indicates a clustering effect that may eventually have a negative effect on the flux. For other types of nanoparticles, Sotto et al. recommend the use of ultralow concentrations for maintaining the beneficial effect of nanostructures used as additives [172].

Mitigation of membrane fouling is another objective, which has been described by Celik et al. [173]. They show that MWCNT/polyethersulfone blend membranes have a better fouling resistance than bare membranes.

6.3. Drug Delivery. Much impact is to be expected from the use of carbon nanotubes in membranes for drug delivery. This application emerged in 2003 when Martin and Kohli [174] suggested nanoparticles as "straws" with a structure that is more beneficial than spherical particles. Hillebrenner et al. [175] describe the advantages of nanotubes over spherical particles; the template is tunable, which means the pore diameter and template thickness can be controlled, resulting in larger payload capacities for nanotubes. The needle-like structure of nanotubes allows for advanced medical applications. For example, the ability of nanotubes to translocate through plasma membranes allows their use for the delivery of therapeutically active molecules in a manner that resembles cell-penetrating peptides [176]. Prato et al. [177] describe how nanotubes open innumerable possibilities for future drug discovery based on intracellular targets that have been hard to reach until today, with the additional advantage that adequately functionalized CNTs can be rapidly eliminated from the body [177].

These features naturally lead to the use of membranes as biomimetic platforms [178] that can be of interest for controlled release of drugs. Zhao et al. [179] successfully used a novel complex of polyoxometalate (an antitumor drug) modified SWCNTs and chitosan for controlled drug release. Im et al. [180] developed an electrosensitive transdermal drug delivery system based on a semi-interpenetrating polymer network as the matrix with polyethylene oxide and pentaerythritol triacrylate polymers. MWCNTs were used as additives to increase the electrical sensitivity. The amount of released drug could be effectively controlled by changing the applied voltage. This is shown in Figure 10.

Other polymers can be used for encapsulation of drugs, with the carbon nanotubes present for release control. Porous membranes made of polycarbonate were used by Perry et al. [181], with the option to include also proteins, DNA, silica, carbon, and chitosan. They developed capping strategies to seal payloads within nanotubes; the resulting structures allowed targeting desired locations for drug release under specific well-considered conditions. Nevertheless, the need for in vivo experiments is emphasized.

Isoporous carbon nanotube membranes may also be used for the barrier function, as shown by Hinds [143]. This would mimic natural protein channels, with a mechanism for dramatically enhanced fluid flow, the ability to place "gatekeeper" chemistry at the entrance to pores, and electrical conductivity.

Furthermore, biological membranes may be mimicked by developing biocomposites from liposomes and carbon nanotubes as vectors for therapeutic molecules [182], which yields stable nanobiocomposites.

6.4. Fuel Cells. The use of carbon nanotubes in membranes for fuel cells is based on their excellent electrical properties. For example, in polymer electrolyte-based fuel cells (PEFCs), carbon nanotubes improve the mechanical strength and proton conductivity of the membrane, and play a role in electrocatalysis [183]. Although most applications of carbon nanotubes in fuel cells are related to their use as electrodes and catalyst support (which is outside the scope of this review), they also play a role in improving the membrane structure. Zhou et al. [184] developed composite membranes consisting of sulfonated carbon nanotubes (sCNTs) and sulfonated poly(ether sulfone ether ketone ketone) for use in fuel cells. They found that the addition of either 

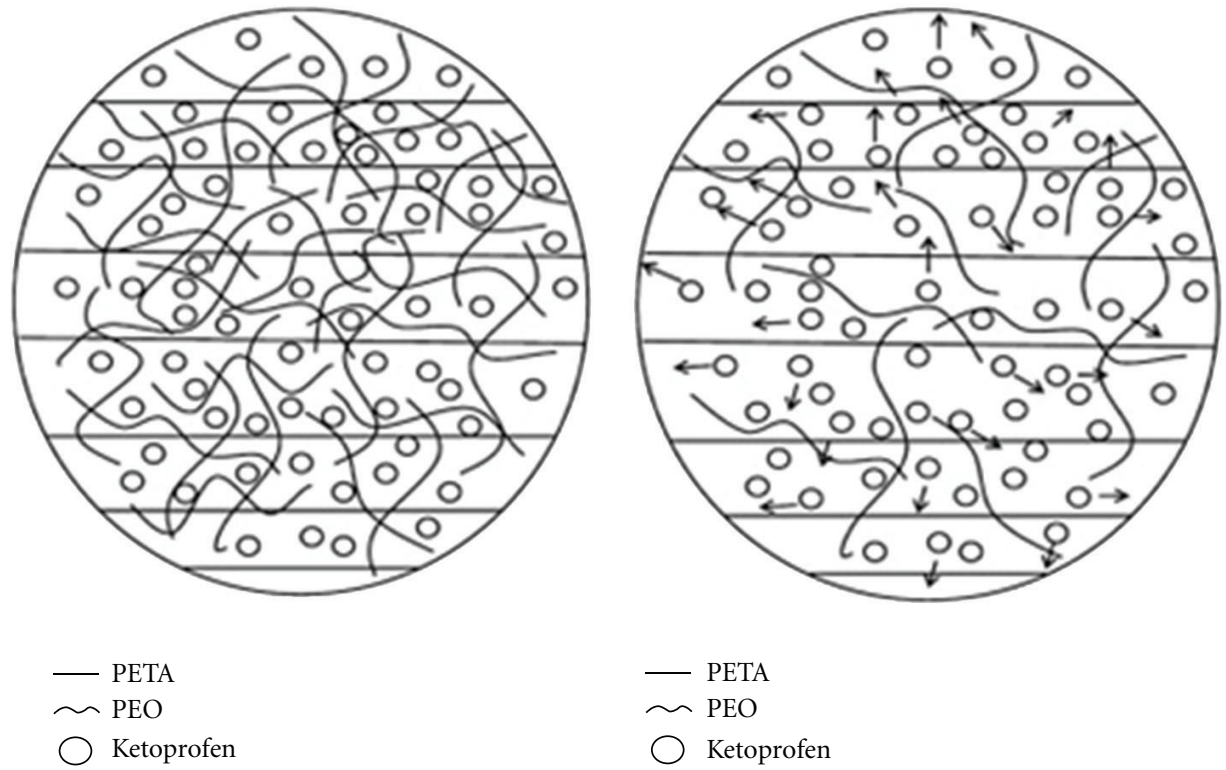

(a)

(b)

Figure 10: Electro-sensitive drug delivery system triggered by MWCNTs in a matrix of polyethylene oxide (PEO) and pentaerythritol triacrylate. Reprinted with permission from Im et al. [180]. (Copyright (2010) Elsevier.)
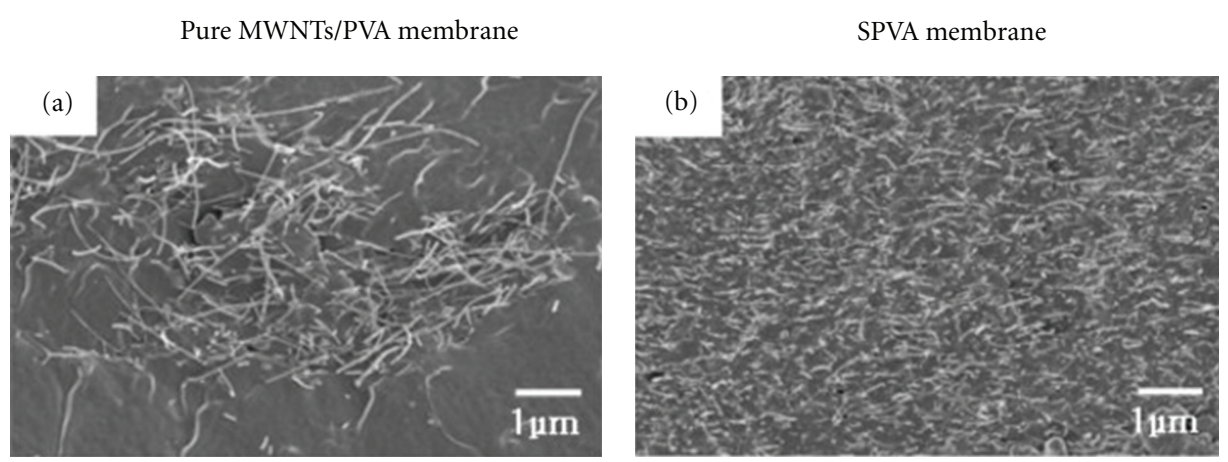

FIGURE 11: Dispersion of pure MWCNTs in PVA (a) and sulfonated MWCNTs in the same polymer (b) for application in direct methanol fuel cells. Reprinted with permission from Im et al. [180]. (Copyright (2010) Elsevier.)

pristine carbon nanotubes or modified carbon nanotubes significantly enhances the tensile strength of the membrane; the proton conductivity increased while the methanol permeability decreased as the sCNTs content increased. In another study [185], PVA was considered for application in direct methanol fuel cells; the polymer consisted of polyvinyl alcohol (PVA), sulfonic acid functionalized CNT, and fluorinated nanoclay (Montmorillonite, MMT). Similarly, Yun et al. [186] used crosslinked sulfonated poly(vinyl alcohol) with sulfonated MWCNTs as proton exchange membranes in direct methanol fuel cells. Sulfonation proves to be a critical factor, not only related to the conductivity of the membrane (as would expected), but also to improve the dispersion in the polymer matrix. This is shown in Figure 11 for PVA [186].

For proton electrolyte membrane fuel cells (PEMFCs) Kannan et al. [187] report on the use of a Nafion-based nanocomposite membrane with inclusion of sulfonic acidfunctionalized multiwalled (s-MWNT) carbon nanotubes into the polymer matrix. They observed an improved proton conductivity, which was related to the presence of sulfonic acid groups, with nanotubes as an anchoring backbone and to improve mechanical properties of the membrane.

A comprehensive overview of the use of nanotubes for use in PEMFC's and DMFC's is given by Thiam et al. [188]. In general, the outlook for using carbon nanotubes in fuel cells has a positive outlook although the use as membrane additives has so far received less attention than the use of nanotubes as catalyst support or in conjunction with the electrodes.

\section{Conclusions}

A wide range of nanotube structures is available for use in membrane structures; most studies focus on a narrow selection of nanomaterials. It has been demonstrated that 
alternative materials (e.g., boron nitride nanotubes) and configurations (such as nanobuds, functionalized SWCNTs and MWCNTs,...) exist that may be beneficial and are yet to be explored. A basic understanding of polymer-nanotube interactions is a prerequisite for successful development of highly performing membranes. Dispersing and aligning nanotubes were identified as critical challenges. Three types of nanotube-based membranes were distinguished: CNT buckypaper, isoporous carbon nanotube membranes in which the nanotubes act as transport channels, and mixed matrix membranes.

Concerning applications, it can be concluded that gas separation is the most advanced and therefore closest to implementation. Many studies concern water filtration, but large-scale applications with high impact such as desalination require more advanced membranes. The use of carbon nanotubes to enhance membrane properties in mixed matrix membranes, however, is thought already feasible.

For drug delivery and controlled release, the potential of nanotubes cannot be underestimated. Nevertheless, hybrid capsules with nanotubes need further development. Lastly, fuel cell applications have a clear potential, which seems restricted by the growth in fuel cells applications as such.

\section{References}

[1] G. Padeletti and P. Fermo, "How the masters in Umbria, Italy, generated and used nanoparticles in art fabrication during the renaissance period," Applied Physics A, vol. 76, no. 4, pp. 515-525, 2003.

[2] J. Wilcoxon, "Optical absorption properties of dispersed gold and silver alloy nanoparticles," Journal of Physical Chemistry B, vol. 113, no. 9, pp. 2647-2656, 2009.

[3] B. Van der Bruggen, J. Haifeng, and J. Kim, "Development of nanofiltration membranes enhanced by deposited and integrated nanoparticles in view of fouling mitigation," in Proceedings of the 7th Ibero-American Conference on Membrane Science and Technology (CITEM '10), pp. 17-18, Oral presentation, Book of Abstracts, Sintra, Portugal, April 2010.

[4] V. J. Morris, "Emerging roles of engineered nanomaterials in the food industry," Trends in Biotechnology, 2011.

[5] F. H. She, W. M. Gao, Z. Peng, P. D. Hodgson, and L. X. Kong, "Micro- and nano-characterization of membrane materials," Journal of the Chinese Institute of Chemical Engineers, vol. 39, no. 4, pp. 313-320, 2008.

[6] W. R. Bowen and T. A. Doneva, "Atomic force microscopy studies of nanofiltration membranes: surface morphology, pore size distribution and adhesion," Desalination, vol. 129, no. 2, pp. 163-172, 2000.

[7] N. S. Kotrappanavar, A. A. Hussain, M. E. E. Abashar, I. S. Al-Mutaz, T. M. Aminabhavi, and M. N. Nadagouda, "Prediction of physical properties of nanofiltration membranes for neutral and charged solutes," Desalination, 2011.

[8] N. C. Mueller, B. Van der Bruggen, V. Keuter et al., "Nanofiltration and nanostructured membranes-should they be considered nanotechnology or not?" Journal of Hazardous Materials, vol. 211-212, pp. 275-280, 2012.

[9] ISO, Nanotechnologies-Vocabulary, Core Terms, International Organisation for Standardisation (ISO), Geneva, Switzerland, 2010.
[10] M. Chakraborty, S. Jain, and V. Rani, "Nanotechnology: emerging tool for diagnostics and therapeutics," Applied Biochemistry and Biotechnology, vol. 165, no. 5-6, pp. 11781187, 2011.

[11] H. C. Huang, S. Barua, G. Sharma, S. K. Dey, and K. Rege, "Inorganic nanoparticles for cancer imaging and therapy," Journal of Controlled Release, 2011.

[12] S. Parveen, R. Misra, and S. K. Sahoo, "Nanoparticles: a boon to drug delivery, therapeutics, diagnostics and imaging," Nanomedicine, vol. 8, no. 2, pp. 147-166, 2012.

[13] E. da Costa, P. P. Zamora, and A. J. G. Zarbin, "Novel $\mathrm{TiO}_{2} / \mathrm{C}$ nanocomposites: synthesis, characterization, and application as a photocatalyst for the degradation of organic pollutants," Journal of Colloid and Interface Science, vol. 368, no. 1, pp. 121-127, 2012.

[14] T.-J. Whang, M.-T. Hsieh, and H.-H. Chen, "Visible-light photocatalytic degradation of methylene blue with laserinduced Ag/ZnO nanoparticles," Applied Surface Science, vol. 258, no. 7, pp. 2796-2801, 2012.

[15] H. P. Li, W. Zheng, S. Y. Huang, and W. Pan, "Enhanced visible-light-driven photocatalysis of surface nitrided electrospun $\mathrm{TiO}_{2}$ nanofibers," Nanoscale, vol. 4, no. 3, pp. 801-806, 2012.

[16] R. D. Noble, "Perspectives on mixed matrix membranes," Journal of Membrane Science, vol. 378, no. 1-2, pp. 393-397, 2011.

[17] M. R. Wiesner and J. Y. Bottero, "A risk forecasting process for nanostructured materials, and nanomanufacturing," Comptes Rendus Physique, vol. 12, no. 7, pp. 659-668, 2011.

[18] W. Aust, N. Daum, M. Bloching et al., "Risk of nanoparticles?” Laryngo- Rhino- Otologie, vol. 88, no. 3, pp. 162-166, 2009.

[19] M. N. Moore, "Do nanoparticles present ecotoxicological risks for the health of the aquatic environment?" Environment International, vol. 32, no. 8, pp. 967-976, 2006.

[20] K. Tiede, M. Hassellöv, E. Breitbarth, Q. Chaudhry, and A. B. A. Boxall, "Considerations for environmental fate and ecotoxicity testing to support environmental risk assessments for engineered nanoparticles," Journal of Chromatography A, vol. 1216, no. 3, pp. 503-509, 2009.

[21] J. Kim and B. Van Der Bruggen, "The use of nanoparticles in polymeric and ceramic membrane structures: review of manufacturing procedures and performance improvement for water treatment," Environmental Pollution, vol. 158, no. 7, pp. 2335-2349, 2010.

[22] A. Sotto, A. Boromand, S. Balta, J. Kim, and B. Van Der Bruggen, "Doping of polyethersulfone nanofiltration membranes: antifouling effect observed at ultralow concentrations of $\mathrm{TiO}_{2}$ nanoparticles," Journal of Materials Chemistry, vol. 21, no. 28, pp. 10311-10320, 2011.

[23] I. Soroko and A. Livingston, "Impact of $\mathrm{TiO}_{2}$ nanoparticles on morphology and performance of crosslinked polyimide organic solvent nanofiltration (OSN) membranes," Journal of Membrane Science, vol. 343, no. 1-2, pp. 189-198, 2009.

[24] J.-F. Li, Z. L. Xu, H. Yang, L. Y. Yu, and M. Liu, "Effect of $\mathrm{TiO}_{2}$ nanoparticles on the surface morphology and performance of microporous PES membrane," Applied Surface Science, vol. 255, no. 9, pp. 4725-4732, 2009.

[25] Y. Yang, H. Zhang, P. Wang, Q. Zheng, and J. Li, “The influence of nano-sized $\mathrm{TiO}_{2}$ fillers on the morphologies and properties of PSF UF membrane," Journal of Membrane Science, vol. 288, no. 1-2, pp. 231-238, 2007. 
[26] S. Balta, A. Sotto, J. Kim, P. Luis, L. Benea, and B. Van der Bruggen, "A new vision on membrane enhancement with nanoparticles: the alternative of $\mathrm{ZnO}$," Journal of Membrane Science, vol. 389, pp. 155-161, 2012.

[27] L. Yan, S. Hong, M. L. Li, and Y. S. Li, "Application of the $\mathrm{Al}_{2} \mathrm{O}_{3}$-PVDF nanocomposite tubular ultrafiltration (UF) membrane for oily wastewater treatment and its antifouling research," Separation and Purification Technology, vol. 66, no. 2, pp. 347-352, 2009.

[28] S. L. Yu, W. X. Shi, Y. Lu, and J. X. Yang, "Characterization and anti-fouling performance of nano- $\mathrm{Al}_{2} \mathrm{O}_{3} / \mathrm{PVDF}$ membrane for Songhua River raw water filtration," Water Science and Technology, vol. 64, no. 9, pp. 1892-1897, 2011.

[29] K. Vanherck, I. Vankelecom, and T. Verbiest, "Improving fluxes of polyimide membranes containing gold nanoparticles by photothermal heating," Journal of Membrane Science, vol. 373, no. 1-2, pp. 5-13, 2011.

[30] J. Xu and D. Bhattacharyya, "Membrane-based bimetallic nanoparticles for environmental remediation: synthesis and reactive properties," Environmental Progress, vol. 24, no. 4, pp. 358-366, 2005.

[31] D. A. P. Tanaka, M. A. L. Tanco, T. Nagase et al., "Fabrication of hydrogen-permeable composite membranes packed with palladium nanoparticles," Advanced Materials, vol. 18, no. 5, pp. 630-632, 2006.

[32] M. M. Pendergast and E. M. V. Hoek, "A review of water treatment membrane nanotechnologies," Energy and Environmental Science, vol. 4, no. 6, pp. 1946-1971, 2011.

[33] B. Haley and E. Frenkel, "Nanoparticles for drug delivery in cancer treatment," Urologic Oncology, vol. 26, no. 1, pp. 5764, 2008.

[34] T. W. Ebbesen, H. J. Lezec, H. Hiura, J. W. Bennett, H. F. Ghaemi, and T. Thio, "Electrical conductivity of individual carbon nanotubes," Nature, vol. 382, no. 6586, pp. 54-56, 1996.

[35] N. Sinha, J. Ma, and J. T. W. Yeow, "Carbon nanotube-based sensors," Journal of Nanoscience and Nanotechnology, vol. 6, no. 3, pp. 573-590, 2006.

[36] O. K. Varghese, P. D. Kichambre, D. Gong, K. G. Ong, E. C. Dickey, and C. A. Grimes, "Gas sensing characteristics of multi-wall carbon nanotubes," Sensors and Actuators B, vol. 81, no. 1, pp. 32-41, 2001.

[37] O. K. Varghese, D. Gong, M. Paulose, K. G. Ong, and C. A. Grimes, "Hydrogen sensing using titania nanotubes," Sensors and Actuators B, vol. 93, no. 1-3, pp. 338-344, 2003.

[38] S. Peng and K. Cho, "Ab initio study of doped carbon nanotube sensors," Nano Letters, vol. 3, no. 4, pp. 513-517, 2003.

[39] Z. Zanolli, R. Leghrib, A. Felten, J. J. Pireaux, E. Llobet, and J. C. Charlier, "Gas sensing with au-decorated carbon nanotubes," ACS Nano, vol. 5, no. 6, pp. 4592-4599, 2011.

[40] J. Bernholc, D. Brenner, M. Buongiorno Nardelli, V. Meunier, and C. Roland, "Mechanical and electrical properties of nanotubes," Annual Review of Materials Science, vol. 32, pp. 347-375, 2002.

[41] J. N. Coleman, U. Khan, W. J. Blau, and Y. K. Gun'ko, "Small but strong: a review of the mechanical properties of carbon nanotube-polymer composites," Carbon, vol. 44, no. 9, pp. 1624-1652, 2006.

[42] A. Oliver, J. Bult, Q. V. Le, A. L. Mbaruku, and J. Schwartz, "Mechanical properties of non-functionalized multiwall nanotube reinforced polycarbonate at $77 \mathrm{~K}$," Nanotechnology, vol. 19, no. 50, Article ID 505702, 2008.
[43] J. Hone, "Carbon nanotubes: thermal properties," in Dekker Encyclopedia of Nanoscience and Nanotechnology, Marcel Dekker, New York, NY, USA, 2004.

[44] R. Che, L. M. Peng, X. Duan, Q. Chen, and X. Liang, "Microwave Absorption Enhancement and Complex Permittivity and Permeability of Fe Encapsulated within Carbon Nanotubes," Advanced Materials, vol. 16, no. 5, pp. 401-405, 2004.

[45] A. Wadhawan, D. Garrett, and J. M. Perez, "Nanoparticleassisted microwave absorption by single-wall carbon nanotubes," Applied Physics Letters, vol. 83, no. 13, pp. 26832685, 2003.

[46] R. C. Che, C. Y. Zhi, C. Y. Liang, and X. G. Zhou, "Fabrication and microwave absorption of carbon nanotubes CoFe $2 \mathrm{O} 4$ spinel nanocomposite," Applied Physics Letters, vol. 88, no. 3, Article ID 033105, pp. 1-3, 2006.

[47] S. Iijima, "Helical microtubules of graphitic carbon," Nature, vol. 354, no. 6348, pp. 56-58, 1991.

[48] P. Levy, A. G. Leyva, H. E. Troiani, and R. D. Sánchez, "Nanotubes of rare-earth manganese oxide," Applied Physics Letters, vol. 83, no. 25, pp. 5247-5249, 2003.

[49] L. Pan, L. Pu, Y. Shi et al., "Synthesis of polyaniline nanotubes with a reactive template of manganese oxide," Advanced Materials, vol. 19, no. 3, pp. 461-464, 2007.

[50] S. W. Lee, J. Kim, S. Chen, P. T. Hammond, and Y. ShaoHorn, "Carbon nanotube/manganese oxide ultrathin film electrodes for electrochemical capacitors," ACS Nano, vol. 4, no. 7, pp. 3889-3896, 2010.

[51] M. E. Spahr, P. Bitterli, R. Nesper, M. Müller, F. Krumeich, and H. U. Nissen, "Redox-active nanotubes of vanadium oxide," Angewandte Chemie, vol. 37, no. 9, pp. 1263-1265, 1998.

[52] F. Krumeich, H. J. Muhr, M. Niederberger, F. Bieri, B. Schnyder, and R. Nesper, "Morphology and topochemical reactions of novel vanadium oxide nanotubes," Journal of the American Chemical Society, vol. 121, no. 36, pp. 8324-8331, 1999.

[53] M. Niederberger, H. J. Muhr, F. Krumeich, F. Bieri, D. Günther, and R. Nesper, "Low-cost synthesis of vanadium oxide nanotubes via two novel non-alkoxide routes," Chemistry of Materials, vol. 12, no. 7, pp. 1995-2000, 2000.

[54] L. Mai, W. Chen, Q. Xu, Q. Zhu, C. Han, and J. Peng, "Costsaving synthesis of vanadium oxide nanotubes," Solid State Communications, vol. 126, no. 10, pp. 541-543, 2003.

[55] A. Yella, E. Mugnaioli, M. Panthöfer, H. A. Therese, U. Kolb, and W. Tremel, "Bismuth-catalyzed growth of SnS2 nanotubes and their stability," Angewandte Chemie, vol. 48, no. 35, pp. 6426-6430, 2009.

[56] M. Nath, A. Govindaraj, and C. N. R. Rao, "Simple synthesis of $\mathrm{MoS}_{2}$ and $\mathrm{WS}_{2}$ nanotubes," Advanced Materials, vol. 13, no. 4, pp. 283-286, 2001.

[57] S. I. Na, S. S. Kim, W. K. Hong et al., "Fabrication of $\mathrm{TiO}_{2}$ nanotubes by using electrodeposited $\mathrm{ZnO}$ nanorod template and their application to hybrid solar cells," Electrochimica Acta, vol. 53, no. 5, pp. 2560-2566, 2008.

[58] X. Zhao, C. M. Hayner, and H. H. Kung, "Self-assembled lithium manganese oxide nanoparticles on carbon nanotube or graphene as high-performance cathode material for lithium-ion batteries," Journal of Materials Chemistry, vol. 21, no. 43, pp. 17297-17303, 2011.

[59] R. L. D. Whitby, W. K. Hsu, P. K. Fearon et al., "Multiwalled carbon nanotubes coated with tungsten disulfide," Chemistry of Materials, vol. 14, no. 5, pp. 2209-2217, 2002. 
[60] M. Brorson, T. W. Hansen, and C. J. H. Jacobsen, "Rhenium(IV) sulfide nanotubes," Journal of the American Chemical Society, vol. 124, no. 39, pp. 11582-11583, 2002.

[61] A. Aqel, K. M. M. A. El-Nour, R. A. A. Ammar, and A. AlWarthan, "Carbon nanotubes, science and technology part (I) structure, synthesis and characterisation," Arabian Journal of Chemistry, 2010.

[62] A. K. Geim and P. Kim, "Carbon wonderland," Scientific American, vol. 298, no. 4, pp. 90-97, 2008.

[63] X. Wang, Q. Li, J. Xie et al., "Fabrication of ultralong and electrically uniform single-walled carbon nanotubes on clean substrates," Nano Letters, vol. 9, no. 9, pp. 3137-3141, 2009.

[64] A. G. Nasibulin, P. V. Pikhitsa, H. Jiang et al., "A novel hybrid carbon material," Nature Nanotechnology, vol. 2, no. 3, pp. 156-161, 2007.

[65] H. Y. He and B. C. Pan, "Electronic structures and Raman features of a carbon nanobud," Journal of Physical Chemistry C, vol. 113, no. 49, pp. 20822-20826, 2009.

[66] X. Zhu and H. Su, "Magnetism in hybrid carbon nanostructures: nanobuds," Physical Review B, vol. 79, no. 16, Article ID 165401, 2009.

[67] M. Wang and C. M. Li, "Magnetic properties of all-carbon graphene-fullerene nanobuds," Physical Chemistry Chemical Physics, vol. 13, no. 13, pp. 5945-5951, 2011.

[68] X. J. Wu and X. C. Zeng, "Periodic graphene nanobuds," Nano Letters, vol. 9, no. 1, pp. 250-256, 2009.

[69] L. Liu, C. S. Jayanthi, and S. Y. Wu, "Structural and electronic properties of a carbon nanotorus: effects of delocalized and localized deformations," Physical Review B, vol. 64, no. 3, Article ID 033412, pp. 0334121-0334124, 2001.

[70] C. P. Liu and N. Xu, "Magnetic response of chiral carbon nanotori: the dependence of torus radius," Physica B, vol. 403, no. 17, pp. 2884-2887, 2008.

[71] B. Sun, "Deformation, vibration, buckling of continuum nanotorus," Journal of Nanomaterials, vol. 2010, Article ID 480628, 2010.

[72] C. A. Kuntscher, A. Abouelsayed, A. Botos, A. Pekker, and K. Kamaras, "Pressure studies on fullerene peapods," Physica Status Solidi B, vol. 248, no. 11, pp. 2732-2735, 2011.

[73] A. Suzuki, T. Oku, and K. Kikuchi, "Electronic structure and magnetic properties of ${ }^{14} \mathrm{~N} @ \mathrm{C}_{60}$ within single-walled carbon nanotube as peapods," Physica B, vol. 405, no. 10, pp. 24182422, 2010.

[74] T. Yanagisawa, T. Hayashi, Y. A. Kim, Y. Fukai, and M. Endo, "Structure and basic properties of cup-stacked type carbon nanofiber," Molecular Crystals and Liquid Crystals Science and Technology A, vol. 387, no. 2, pp. 391-]/167-[395]/171, 2002.

[75] M. Inagaki, K. Kaneko, and T. Nishizawa, "Nanocarbonsrecent research in Japan," Carbon, vol. 42, no. 8-9, pp. 14011417, 2004.

[76] T. Murmu, S. Adhikari, and C. Y. Wang, "Torsional vibration of carbon nanotube-buckyball systems based on nonlocal elasticity theory," Physica E, vol. 43, no. 6, pp. 1276-1280, 2011.

[77] C. Kim, Y. J. Kim, Y. A. Kim et al., "High performance of cupstacked-type carbon nanotubes as a Pt-Ru catalyst support for fuel cell applications," Journal of Applied Physics, vol. 96, no. 10, pp. 5903-5905, 2004.

[78] Q. Liu, W. Ren, B. Liu et al., "Synthesis, purification and opening of short cup-stacked carbon nanotubes," Journal of Nanoscience and Nanotechnology, vol. 9, no. 8, pp. 4554-4560, 2009.

[79] Y. A. Kim, T. Hayashi, S. Naokawa, T. Yanagisawa, and M. Endo, "Comparative study of herringbone and stacked-cup carbon nanofibers," Carbon, vol. 43, no. 14, pp. 3005-3008, 2005.

[80] A. N. Sohi and R. Naghdabadi, "Stability of single-walled carbon nanopeapods under combined axial compressive load and external pressure," Physica E, vol. 41, no. 3, pp. 513-517, 2009.

[81] H. Kuzmany, A. Kukovecz, F. Simon, M. Holzweber, C. Kramberger, and T. Pichler, "Functionalization of carbon nanotubes," Synthetic Metals, vol. 141, no. 1-2, pp. 113-122, 2004.

[82] B. Vigolo, V. Mamane, F. Valsaque et al., "Evidence of sidewall covalent functionalization of single-walled carbon nanotubes and its advantages for composite processing," Carbon, vol. 47, no. 2, pp. 411-419, 2009.

[83] P. Blondeau, F. X. Rius-Ruiz, A. Duzgun, J. Riu, and F. X. Rius, "Covalent functionalization of single-walled carbon nanotubes with adenosine monophosphate: towards the synthesis of SWCNT-Aptamer hybrids," Materials Science and Engineering C, vol. 31, no. 7, pp. 1363-1368, 2011.

[84] A. Khazaei, M. N. S. Rad, M. K. Borazjani, S. Saednia, M. K. Borazjani, and D. Soudbar, "Functionalization of singlewalled carbon nanotubes with 4-benzo-9-crown-3 ether," Synlett, no. 15, Article ID B01411ST, pp. 2145-2150, 2011.

[85] S. Akbar and A. A. Taimoor, "Functionalization of carbon nanotubes: manufacturing techniques and properties of customized nanocomponents for molecular-level technology," Recent Patents on Nanotechnology, vol. 3, no. 2, pp. 154-161, 2009.

[86] A. L. Alpatova, W. Shan, P. Babica et al., "Single-walled carbon nanotubes dispersed in aqueous media via non-covalent functionalization: effect of dispersant on the stability, cytotoxicity, and epigenetic toxicity of nanotube suspensions," Water Research, vol. 44, no. 2, pp. 505-520, 2010.

[87] A. Ghosh, K. V. Rao, R. Voggu, and S. J. George, "Noncovalent functionalization, solubilization of graphene and single-walled carbon nanotubes with aromatic donor and acceptor molecules," Chemical Physics Letters, vol. 488, no. 46, pp. 198-201, 2010.

[88] H. Chen, H. Xiong, Y. Gao, and H. Li, "Covalent functionalization of multiwalled carbon nanotubes with polybutadiene," Journal of Applied Polymer Science, vol. 116, no. 3, pp. 1272-1277, 2010.

[89] C. M. Hussain, C. Saridara, and S. Mitra, "Modifying the sorption properties of multi-walled carbon nanotubes via covalent functionalization," Analyst, vol. 134, no. 9, pp. 19281933, 2009.

[90] C. Salvador-Morales, E. V. Basiuk, V. A. Basiuk, M. L. H. Green, and R. B. Sim, "Effects of covalent functionalization on the biocompatibility characteristics of multi-walled carbon nanotubes," Journal of Nanoscience and Nanotechnology, vol. 8, no. 5, pp. 2347-2356, 2008.

[91] Q. Shi, D. Yang, Y. Su et al., "Covalent functionalization of multi-walled carbon nanotubes by lipase," Journal of Nanoparticle Research, vol. 9, no. 6, pp. 1205-1210, 2007.

[92] J. Liu, O. Bibari, P. Mailley et al., "Stable non-covalent functionalisation of multi-walled carbon nanotubes by pyrenepolyethylene glycol through pi-pi stacking," New Journal of Chemistry, vol. 33, no. 5, pp. 1017-1024, 2009.

[93] X. Li, S. Y. Wong, W. C. Tjiu, B. P. Lyons, S. A. Oh, and C. B. $\mathrm{He}$, "Non-covalent functionalization of multi walled carbon nanotubes and their application for conductive composites," Carbon, vol. 46, no. 5, pp. 829-831, 2008. 
[94] B. J. Hinds, N. Chopra, T. Rantell, R. Andrews, V. Gavalas, and L. G. Bachas, "Aligned Multiwalled Carbon Nanotube Membranes," Science, vol. 303, no. 5654, pp. 62-65, 2004.

[95] Y. K. Choi, Y. Gotoh, K. I. Sugimoto, S. M. Song, T. Yanagisawa, and M. Endo, "Processing and characterization of epoxy nanocomposites reinforced by cup-stacked carbon nanotubes," Polymer, vol. 46, no. 25, pp. 11489-11498, 2005.

[96] M. Rahmat and P. Hubert, "Carbon nanotube-polymer interactions in nanocomposites: a review," Composites Science and Technology, vol. 72, no. 1, pp. 72-84, 2011.

[97] H. K. F. Cheng, Y. Z. Pan, N. G. Sahoo et al., "Improvement in properties of multiwalled carbon nanotube/polypropylene nanocomposites through homogeneous dispersion with the aid of surfactants," Journal of Applied Polymer Science, vol. 124, no. 2, pp. 1117-1127, 2012.

[98] C.-R. Yu, D.-M. Wu, Y. Liu et al., "Electrical and dielectric properties of polypropylene nanocomposites based on carbon nanotubes and barium titanate nanoparticles," Composites Science and Technology, vol. 71, no. 15, pp. 1706-1712, 2011.

[99] X. H. Peng, M. X. Li, H. W. Zou, P. Fan, and P. B. Liu, "Morphology and properties of functionalised MWNT/ polypropylene composites," Rubber \& Plastics Company, vol. 41, no. 1, pp. 23-28, 2012.

[100] J. Yu, K. Peng, X. L. Gong, and Z. Zhang, "Creep and recovery of polypropylene/carbon nanotube composites," International Journal of Plasticity, vol. 27, no. 8, pp. 1239-1251, 2011.

[101] Y. Ngabonziza, J. Li, and C. F. Barry, "Electrical conductivity and mechanical properties of multiwalled carbon nanotubereinforced polypropylene nanocomposites," Acta Mechanica, vol. 220, no. 1-4, pp. 289-298, 2011.

[102] D. R. Yu and G. H. Kim, "Effect of processing parameters on the surface resistivity of ethylene-vinyl acetate copolymer/multiwalled carbon nanotube nanocomposites," Journal of Applied Polymer Science, vol. 124, no. 4, pp. 2962-2967, 2012.

[103] R. Wen, K. Ke, Y. Wang, B. H. Xie, and M. B. Yang, "Interfacial interaction of polyvinylidene fluoride/multiwalled carbon nanotubes nanocomposites: a rheological study," Journal of Applied Polymer Science, vol. 212, no. 5, pp. 3041-3046, 2011.

[104] M. Kato, A. Usuki, N. Hasegawa, H. Okamoto, and M. Kawasumi, "Development and applications of polyolefinand rubber-clay nanocomposites," Polymer Journal, vol. 43, no. 7, pp. 583-593, 2011.

[105] B. K. Singh, P. Kar, N. K. Shrivastava, S. Banerjee, and B. B. Khatua, "Electrical and mechanical properties of acrylonitrile-butadiene-styrene/multiwall carbon nanotube nanocomposites prepared by melt-blending," Journal of Applied Polymer Science, vol. 124, no. 4, pp. 3165-3174, 2012.

[106] Z. Jiang, P. Hornsby, R. McCool, and A. Murphy, "Mechanical and thermal properties of polyphenylene sulfide/multiwalled carbon nanotube composites," Journal of Applied Polymer Science, vol. 123, no. 5, pp. 2676-2683, 2012.

[107] A. May-Pat, F. Aviles, P. Toro, M. Yazdani-Pedram, and J. V. Cauich-Rodriguez, "Mechanical properties of PET composites using multiwalled carbon nanotubes functionalized by inorganic and itaconic acids," Express Polymer Letters, vol. 6, no. 2, pp. 96-106, 2012.

[108] M. R. Loos and K. Schulte, "Is it worth the effort to reinforce polymers with carbon nanotubes?" Macromolecular Theory and Simulations, vol. 20, no. 5, pp. 350-362, 2011.

[109] Y. Wang, Z. Xu, L. Chen, Y. Jiao, and X. Wu, "Multiscale hybrid composites-based carbon nanotubes," Polymer Composites, vol. 32, no. 2, pp. 159-167, 2011.
[110] M. Razavi-Nouri, "Effect of carbon nanotubes on dynamic mechanical properties, TGA, and crystalline structure of polypropylene," Journal of Applied Polymer Science, vol. 124, no. 3, pp. 2541-2549, 2012.

[111] X. Q. Liu, W. Yang, B. H. Xie, and M. B. Yang, "Influence of multiwall carbon nanotubes on the morphology, melting, crystallization and mechanical properties of polyamide 6/acrylonitrile-butadiene-styrene blends," Materials \& Design, vol. 34, pp. 355-362, 2012.

[112] B. X. Du and Z. P. Fang, "Effects of carbon nanotubes on the thermal stability and flame retardancy of intumescent flameretarded polypropylene," Polymer Degradation and Stability, vol. 96, no. 10, pp. 1725-1731, 2011.

[113] M. Supova, G. S. Martynkova, and K. Barabaszova, "Effect of nanofillers dispersion in polymer matrices: a review," Science of Advanced Materials, vol. 3, no. 1, pp. 1-25, 2011.

[114] M. H. Al-Saleh and U. Sundararaj, "Review of the mechanical properties of carbon nanofiber/polymer composites," Composites A, vol. 42, no. 12, pp. 2126-2142, 2011.

[115] A. Thess, R. Lee, P. Nikolaev et al., "Crystalline ropes of metallic carbon nanotubes," Science, vol. 273, no. 5274, pp. 483-487, 1996.

[116] Y. An, X. T. He, W. M. Yang, and Y. M. Ding, "Effect of surfactants on the dispersion of multi-walled carbon nanotubes in epoxy resin," in Advanced Polymer Science and Engineering, C. H. Wang, L. X. Ma, and W. Yang, Eds., pp. 1-7, Trans TechPublications, Zurich, Switserland, 2011.

[117] N. Diouri and M. Baitoul, "Studies of multiwall carbon nanotubes (MWCNTS) dispersion in poly vinyl alcohol (PVA)," Mediterranean Journal of Electronics and Communications, vol. 6, no. 1, pp. 18-22, 2010.

[118] H. Wang, "Dispersing carbon nanotubes using surfactants," Current Opinion in Colloid and Interface Science, vol. 14, no. 5, pp. 364-371, 2009.

[119] G. C. Papanicolaou, K. P. Papaefthymiou, A. F. Koutsomitopoulou, D. V. Portan, and S. P. Zaoutsos, "Effect of dispersion of MWCNTs on the static and dynamic mechanical behavior of epoxy matrix nanocomposites," Journal of Materials Science, vol. 47, no. 1, pp. 350-359, 2012.

[120] E. C. Botelho, E. R. Edwards, B. Bittmann, and T. Burkhart, "Dispersing carbon nanotubes in phenolic resin using an aqueous solution," Journal of the Brazilian Chemical Society, vol. 22, no. 11, pp. 2040-2047, 2011.

[121] K. Mukhopadhyay, C. D. Dwivedi, and G. N. Mathur, "Conversion of carbon nanotubes to carbon nanofibers by sonication," Carbon, vol. 40, no. 8, pp. 1373-1376, 2002.

[122] N. Grossiord, J. Loos, O. Regev, and C.E. Koning, “Toolbox for dispersing carbon nanotubes into polymers to get conductive nanocomposites," Chemistry of Materials, vol. 18, no. 5, pp. 1089-1099, 2006.

[123] J. K. W. Sandler, J. E. Kirk, I. A. Kinloch, M. S. P. Shaffer, and A. H. Windle, "Ultra-low electrical percolation threshold in carbon-nanotube-epoxy composites," Polymer, vol. 44, no. 19, pp. 5893-5899, 2003.

[124] J. Sandler, M. S. P. Shaffer, T. Prasse, W. Bauhofer, K. Schulte, and A. H. Windle, "Development of a dispersion process for carbon nanotubes in an epoxy matrix and the resulting electrical properties," Polymer, vol. 40, no. 21, pp. 5967-5971, 1999.

[125] J. L. Bahr and J. M. Tour, "Covalent chemistry of single-wall carbon nanotubes," Journal of Materials Chemistry, vol. 12, no. 7, pp. 1952-1958, 2002. 
[126] S. J. Park, M. S. Cho, S. T. Lim, H. J. Choi, and M. S. Jhon, "Synthesis and dispersion characteristics of multi-walled carbon nanotube composites with poly(methyl methacrylate) prepared by in-situ bulk polymerization," Macromolecular Rapid Communications, vol. 24, no. 18, pp. 1070-1073, 2003.

[127] M. S. P. Shaffer and K. Koziol, "Polystyrene grafted multiwalled carbon nanotubes," Chemical Communications, no. 18, pp. 2074-2075, 2002.

[128] J. Chen, H. Liu, W. A. Weimer, M. D. Halls, D. H. Waldeck, and G. C. Walker, "Noncovalent engineering of carbon nanotube surfaces by rigid, functional conjugated polymers," Journal of the American Chemical Society, vol. 124, no. 31, pp. 9034-9035, 2002.

[129] G. B. Blanchet, C. R. Fincher, and F. Gao, "Polyaniline nanotube composites: a high-resolution printable conductor," Applied Physics Letters, vol. 82, no. 8, pp. 1290-1292, 2003.

[130] W. Feng, X. D. Bai, Y. Q. Lian, J. Liang, X. G. Wang, and K. Yoshino, "Well-aligned polyaniline/carbon-nanotube composite films grown by in-situ aniline polymerization," Carbon, vol. 41, no. 8, pp. 1551-1557, 2003.

[131] H. Zengin, W. Zhou, J. Jin et al., "Carbon nanotube doped polyaniline," Advanced Materials, vol. 14, no. 20, pp. 14801483, 2002.

[132] C. Park, Z. Ounaies, K. A. Watson et al., "Dispersion of single wall carbon nanotubes by in situ polymerization under sonication," Chemical Physics Letters, vol. 364, no. 3-4, pp. 303-308, 2002.

[133] R. Ramasubramaniam, J. Chen, and H. Liu, "Homogeneous carbon nanotube/polymer composites for electrical applications," Applied Physics Letters, vol. 83, no. 14, pp. 2928-2930, 2003.

[134] H. Cebeci, R. G. D. Villoria, A. J. Hart, and B. L. Wardle, "Multifunctional properties of high volume fraction aligned carbon nanotube polymer composites with controlled morphology," Composites Science and Technology, vol. 69, no. 1516, pp. 2649-2656, 2009.

[135] X. L. Xie, Y. W. Mai, and X. P. Zhou, "Dispersion and alignment of carbon nanotubes in polymer matrix: a review," Materials Science and Engineering R, vol. 49, no. 4, pp. 89$112,2005$.

[136] P. S. Goh, A. F. Ismail, S. M. Sanip, B. C. Ng, and M. Aziz, "Recent advances of inorganicfillers in mixed matrix membrane for gas separation," Separation and Purification Technology, vol. 81, no. 3, pp. 243-264, 2011.

[137] K. Sears, L. Dumee, J. Schutz et al., "Recent developments in carbon nanotube membranes for water purification and gas separation," Materials, vol. 3, no. 1, pp. 127-149, 2010.

[138] L. F. Dumee, K. Sears, J. Schutz et al., "Characterization and evaluation of carbon nanotube Bucky-Paper membranes for direct contact membrane distillation," Journal of Membrane Science, vol. 351, no. 1-2, pp. 36-43, 2010.

[139] L. Dumee, V. Germain, K. Sears et al., "Enhanced durability and hydrophobicity of carbon nanotube bucky paper membranes in membrane distillation," Journal of Membrane Science, vol. 376, no. 1-2, pp. 241-246, 2011.

[140] S. Karan, S. Samitsu, X. Peng, K. Kurashima, and I. Ichinose, "Ultrafast viscous permeation of organic solvents through diamond-like carbon nanosheets," Science, vol. 335, no. 6067, pp. 444-447, 2012.

[141] Q. Chen, L. Meng, Q. Li et al., "Water transport and purification in nanochannels controlled by asymmetric wettability," Small, vol. 7, no. 15, pp. 2225-2231, 2011.
[142] M. Majumder, N. Chopra, and B. J. Hinds, "Effect of tip functionalization on transport through vertically oriented carbon nanotube membranes," Journal of the American Chemical Society, vol. 127, no. 25, pp. 9062-9070, 2005.

[143] B. Hinds, "Dramatic transport properties of carbon nanotube membranes for a robust protein channel mimetic platform," Current Opinion in Solid State and Materials Science, vol. 16, no. 1, pp. 1-9, 2012.

[144] P. Nednoor, V. G. Gavalas, N. Chopra, B. J. Hinds, and L. G. Bachas, "Carbon nanotube based biomimetic membranes: mimicking protein channels regulated by phosphorylation," Journal of Materials Chemistry, vol. 17, no. 18, pp. 1755-1757, 2007.

[145] Z. Mao and S. B. Sinnott, "Separation of organic molecular mixtures in carbon nanotubes and bundles: molecular dynamics simulations," Journal of Physical Chemistry B, vol. 105, no. 29, pp. 6916-6924, 2001.

[146] A. I. Skoulidas, D. M. Ackerman, J. K. Johnson, and D. S. Sholl, "Rapid transport of gases in carbon nanotubes," Physical Review Letters, vol. 89, no. 18, pp. 185901/1-185901/4, 2002.

[147] S. Joseph and N. R. Aluru, "Why are carbon nanotubes fast transporters of water?" Nano Letters, vol. 8, no. 2, pp. 452458, 2008.

[148] O. Bakhtiari, S. Mosleh, T. Khosravi, and T. Mohammadi, "Synthesis and characterization of polyimide mixed matrix membranes," Separation Science and Technology, vol. 46, no. 13, pp. 2138-2147, 2011.

[149] Y. Mansourpanah, S. S. Madaeni, A. Rahimpour, M. Adeli, M. Y. Hashemi, and M. R. Moradian, "Fabrication new PES-based mixed matrix nanocomposite membranes using polycaprolactone modified carbon nanotubes as the additive: property changes and morphological studies," Desalination, vol. 277, no. 1-3, pp. 171-177, 2011.

[150] A. F. Ismail, N. H. Rahim, A. Mustafa et al., "Gas separation performance of polyethersulfone/multi-walled carbon nanotubes mixed matrix membranes," Separation and Purification Technology, vol. 80, no. 1, pp. 20-31, 2011.

[151] P. S. Goh, B. C. Ng, A. F. Ismail, S. M. Sanip, M. Aziz, and M. A. Kassim, "Effect of dispersed multi-walled carbon nanotubes on mixed matrix membrane for O2/N2 separation," Separation Science and Technology, vol. 46, no. 8, pp. 12501261, 2011.

[152] L. Ge, Z. Zhu, and V. Rudolph, "Enhanced gas permeability by fabricating functionalized multi-walled carbon nanotubes and polyethersulfone nanocomposite membrane," Separation and Purification Technology, vol. 78, no. 1, pp. 76-82, 2011.

[153] S. Qiu, L. Wu, G. Shi, L. Zhang, H. Chen, and C. Gao, "Preparation and pervaporation property of chitosan membrane with functionalized multiwalled carbon nanotubes," Industrial and Engineering Chemistry Research, vol. 49, no. 22, pp. 11667-11675, 2010.

[154] H. Cong, J. Zhang, M. Radosz, and Y. Shen, "Carbon nanotube composite membranes of brominated poly(2,6diphenyl-1,4-phenylene oxide) for gas separation," Journal of Membrane Science, vol. 294, no. 1-2, pp. 178-185, 2007.

[155] G. Arora and S. I. Sandler, "Air separation by single wall carbon nanotubes: mass transport and kinetic selectivity," Journal of Chemical Physics, vol. 124, no. 8, 2006.

[156] H. Chen and D. S. Sholl, "Predictions of selectivity and flux for $\mathrm{CH} 4 / \mathrm{H} 2$ separations using single walled carbon nanotubes as membranes," Journal of Membrane Science, vol. 269, no. 1-2, pp. 152-160, 2006. 
[157] A. I. Skoulidas, D. S. Sholl, and J. K. Johnson, "Adsorption and diffusion of carbon dioxide and nitrogen through singlewalled carbon nanotube membranes," Journal of Chemical Physics, vol. 124, no. 5, Article ID 054708, pp. 1-7, 2006.

[158] G. Arora and S. I. Sandler, "Molecular sieving using single wall carbon nanotubes," Nano Letters, vol. 7, no. 3, pp. 565569, 2007.

[159] K. Sangil, J. R. Jinschek, H. Chen, D. S. Sholl, and E. Marand, "Scalable fabrication of carbon nanotube/polymer nanocomposite membranes for high flux gas transport," Nano Letters, vol. 7, no. 9, pp. 2806-2811, 2007.

[160] A. A. Gusev and O. Guseva, "Rapid mass transport in mixed matrix nanotube/polymer membranes," Advanced Materials, vol. 19, no. 18, pp. 2672-2676, 2007.

[161] A. Sharma, S. Kumar, B. Tripathi, M. Singh, and Y. K. Vijay, "Aligned CNT/Polymer nanocomposite membranes for hydrogen separation," International Journal of Hydrogen Energy, vol. 34, no. 9, pp. 3977-3982, 2009.

[162] T. H. Weng, H. H. Tseng, and M. Y. Wey, "Preparation and characterization of multi-walled carbon nanotube/PBNPI nanocomposite membrane for $\mathrm{H} 2 / \mathrm{CH} 4$ separation," International Journal of Hydrogen Energy, vol. 34, no. 20, pp. 87078715, 2009.

[163] M. A. Aroon, A. F. Ismail, M. M. Montazer-Rahmati, and T. Matsuura, "Effect of raw multi-wall carbon nanotubes on morphology and separation properties of polyimide membranes," Separation Science and Technology, vol. 45, no. 16, pp. 2287-2297, 2010.

[164] R. S. Murali, S. Sridhar, T. Sankarshana, and Y. V. L. Ravikumar, "Gas permeation behavior of pebax-1657 nanocomposite membrane incorporated with multiwalled carbon nanotubes," Industrial and Engineering Chemistry Research, vol. 49, no. 14, pp. 6530-6538, 2010.

[165] M. Elimelech and W. A. Phillip, "The future of seawater desalination: energy, technology, and the environment," Science, vol. 333, no. 6043, pp. 712-717, 2011.

[166] B. Corry, "Designing carbon nanotube membranes for efficient water desalination," Journal of Physical Chemistry B, vol. 112, no. 5, pp. 1427-1434, 2008.

[167] K. P. Lee, T. C. Arnot, and D. Mattia, "A review of reverse osmosis membrane materials for desalination-Development to date and future potential," Journal of Membrane Science, vol. 370, no. 1-2, pp. 1-22, 2011.

[168] T. A. Hilder, D. Gordon, and S. H. Chung, "Salt rejection and water transport through boron nitride nanotubes," Small, vol. 5, no. 19, pp. 2183-2190, 2009.

[169] B. Zhao, L. Zhang, X.-Y. Wang et al., "Research progress in nanofiltration membrane based on carbon nanotubes," New Carbon Materials, vol. 26, no. 5, pp. 321-327, 2011.

[170] H. A. Shawky, S. R. Chae, S. Lin, and M. R. Wiesner, "Synthesis and characterization of a carbon nanotube/polymer nanocomposite membrane for water treatment," Desalination, vol. 272, no. 1-3, pp. 46-50, 2011.

[171] J. H. Choi, J. Jegal, and W. N. Kim, "Fabrication and characterization of multi-walled carbon nanotubes/polymer blend membranes," Journal of Membrane Science, vol. 284, no. 1-2, pp. 406-415, 2006.

[172] A. Sotto, A. Boromand, S. Balta, J. Kim, and B. Van Der Bruggen, "Doping of polyethersulfone nanofiltration membranes: antifouling effect observed at ultralow concentrations of $\mathrm{TiO}_{2}$ nanoparticles," Journal of Materials Chemistry, vol. 21, no. 28, pp. 10311-10320, 2011.

[173] E. Celik, H. Park, H. Choi, and H. Choi, "Carbon nanotube blended polyethersulfone membranes for fouling control in water treatment," Water Research, vol. 45, no. 1, pp. 274-282, 2011.

[174] C. R. Martin and P. Kohli, "The emerging field of nanotube biotechnology," Nature Reviews Drug Discovery, vol. 2, no. 1, pp. 29-37, 2003.

[175] H. Hillebrenner, F. Buyukserin, J. D. Stewart, and C. R. Martin, "Template synthesized nanotubes for biomedical delivery applications," Nanomedicine, vol. 1, no. 1, pp. 39-50, 2006.

[176] L. Lacerda, S. Raffa, M. Prato, A. Bianco, and K. Kostarelos, "Cell-penetrating CNTs for delivery of therapeutics," Nano Today, vol. 2, no. 6, pp. 38-43, 2007.

[177] M. Prato, K. Kostarelos, and A. Bianco, "Functionalized carbon nanotubes in drug design and discovery," Accounts of Chemical Research, vol. 41, no. 1, pp. 60-68, 2008.

[178] B. J. Hinds, "INOR 556-Aligned carbon nanotube membranes as dramatic fluid flow and biomimetic platforms," Abstracts of Papers American Chemical Society, vol. 235, p. 556-INOR, 2008.

[179] Q. Zhao, X. Feng, S. Mei, and Z. Jin, "Carbon-nanotubeassisted high loading and controlled release of polyoxometalates in biodegradable multilayer thin films," Nanotechnology, vol. 20, no. 10, Article ID 105101, 2009.

[180] J. S. Im, B. C. Bai, and Y. S. Lee, "The effect of carbon nanotubes on drug delivery in an electro-sensitive transdermal drug delivery system," Biomaterials, vol. 31, no. 6, pp. 14141419, 2010.

[181] J. L. Perry, C. R. Martin, and J. D. Stewart, "Drug-delivery strategies by using template-synthesized nanotubes," Chemistry, vol. 17, no. 23, pp. 6296-6302, 2011.

[182] M. E. B. Patrascu, A. Cojocariu, L. Tugulea, N. M. Badea, I. Lacatusu, and A. Meghea, "Nanostructures with liposomes and carbon nanotubese," Journal of Optoelectronics and Advanced Materials, vol. 13, no. 9, pp. 1153-1158, 2011.

[183] W. Zhang, S. Ravi, and P. Silva, "Application of carbon nanotubes in polymer electrolyte based fuel cells," Reviews on Advanced Materials Science, vol. 29, no. 1, pp. 1-14, 2011.

[184] W. H. Zhou, J. Xiao, Y. W. Chen et al., "Sulfonated carbon nanotubes/sulfonated poly (ether sulfone ether ketone ketone) composites for polymer electrolyte membranes," Polymers for Advanced Technologies, vol. 22, no. 12, pp. 17471752, 2011.

[185] J. Maiti, N. Kakati, S. H. Lee, S. H. Jee, and Y. S. Yoon, "PVA nano composite membrane for DMFC application," Solid State Ionics, vol. 201, no. 1, pp. 21-26, 2011.

[186] S. Yun, H. Im, Y. Heo, and J. Kim, "Crosslinked sulfonated poly(vinyl alcohol)/sulfonated multi-walled carbon nanotubes nanocomposite membranes for direct methanol fuel cells," Journal of Membrane Science, vol. 380, no. 1-2, pp. 208-215, 2011.

[187] R. Kannan, M. Parthasarathy, S. U. Maraveedu, S. Kurungot, and V. K. Pillai, "Domain size manipulation of perflouorinated polymer electrolytes by sulfonic acid-functionalized MWCNTs to enhance fuel cell performance," Langmuir, vol. 25, no. 14, pp. 8299-8305, 2009.

[188] H. S. Thiam, W. R. W. Daud, S. K. Kamarudin et al., "Overview on nanostructured membrane in fuel cell applications," International Journal of Hydrogen Energy, vol. 36, no. 4, pp. 3187-3205, 2011.

[189] Y. L. Zhao and J. F. Stoddart, "Noncovalent functionalization of single-walled carbon nanotubes," Accounts of Chemical Research, vol. 42, no. 8, pp. 1161-1171, 2009. 

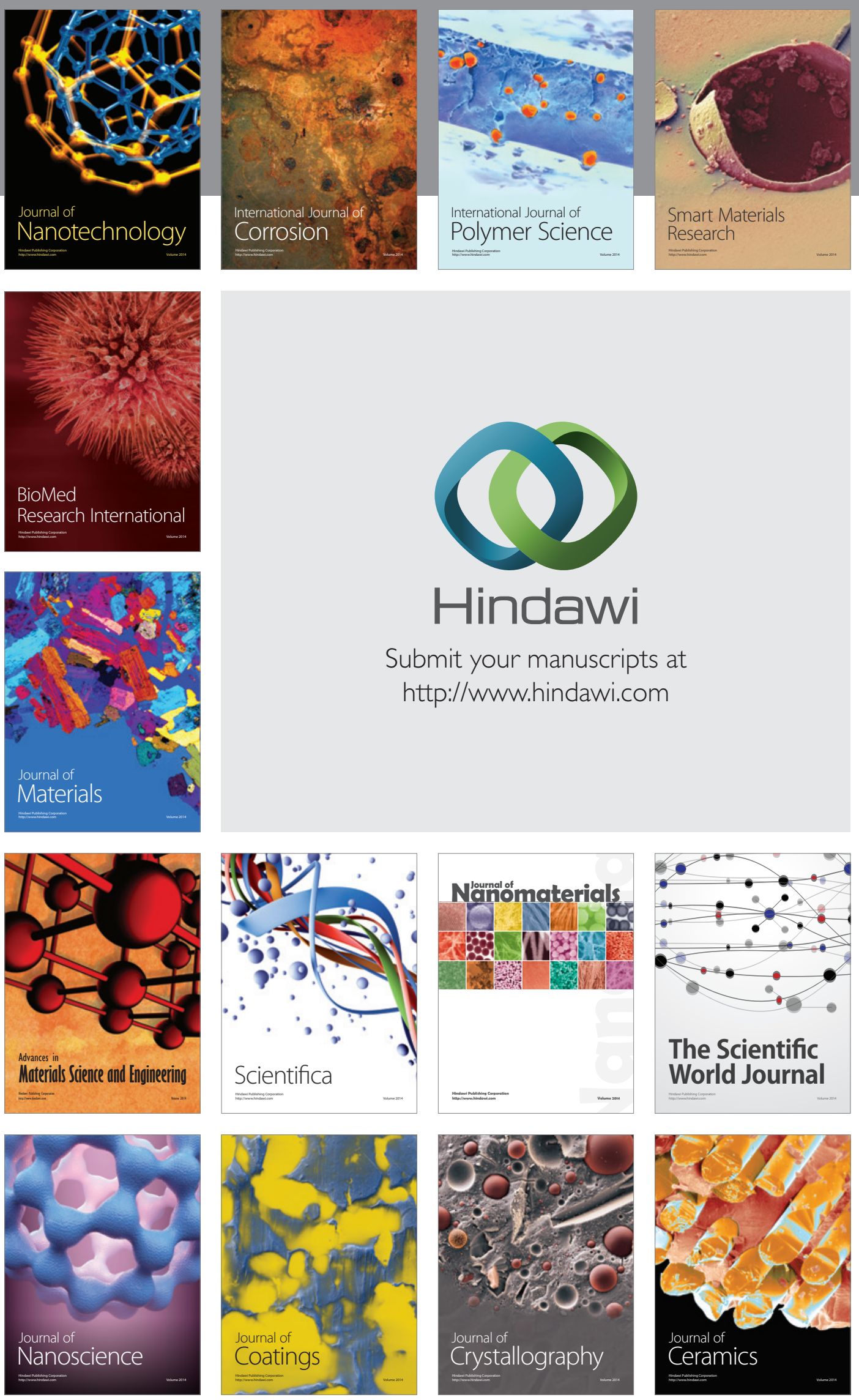

The Scientific World Journal

Submit your manuscripts at

http://www.hindawi.com

\section{World Journal}

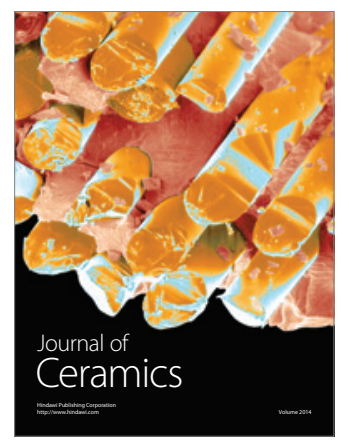

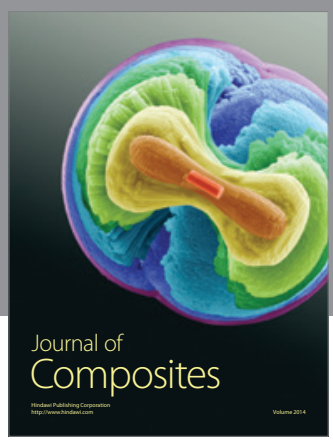
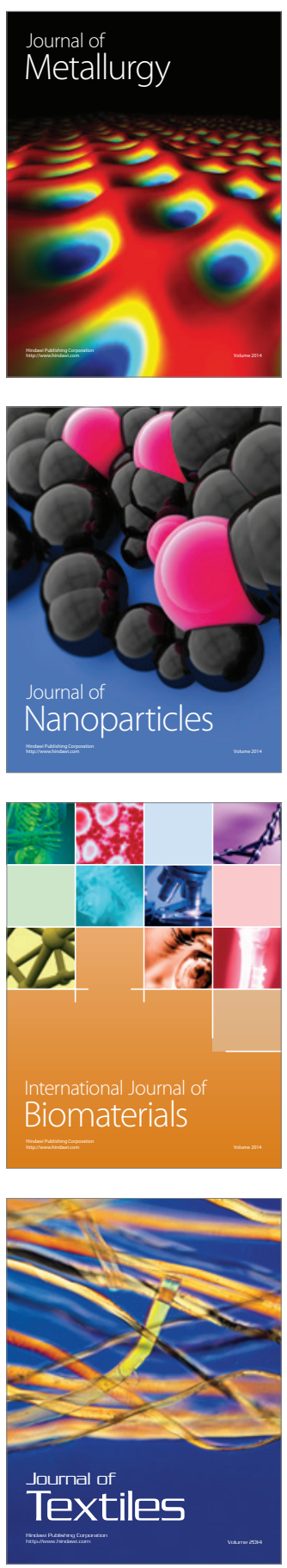